Review

\title{
PSMA Ligands for Radionuclide Imaging and Therapy of Prostate Cancer: Clinical Status
}

\author{
Susanne Lütje ${ }^{1,2,}$, Sandra Heskamp², Alexander S. Cornelissen², Thorsten D. Poeppel1, Sebastiaan A. M. \\ W. van den Broek ${ }^{3}$, Sandra Rosenbaum-Krumme ${ }^{1}$, Andreas Bockisch'1, Martin Gotthardt², Mark Rijpkema ${ }^{2}$, \\ Otto C. Boerman ${ }^{2}$ \\ 1. Department of Nuclear Medicine, University Medical Center Essen, University Duisburg-Essen, Germany \\ 2. Department of Radiology and Nuclear Medicine, Radboud University Medical Center, Nijmegen, The Netherlands \\ 3. FutureChemistry Holding BV, Nijmegen, The Netherlands \\ $\triangle$ Corresponding author: Susanne Lütje, MD, PhD, University Medical Center Essen, Department of Nuclear Medicine, Hufelandstraße 55, 45122 \\ Essen, Germany. Phone: +49 201 - 723 83663; Email: Susanne.Luetje@uk-essen.de
}

C 2015 Ivyspring International Publisher. Reproduction is permitted for personal, noncommercial use, provided that the article is in whole, unmodified, and properly cited. See http://ivyspring.com/terms for terms and conditions.

Received: 2015.07.27; Accepted: 2015.08.31; Published: 2015.10.18

\begin{abstract}
Prostate cancer $(\mathrm{PCa})$ is the most common malignancy in men worldwide, leading to substantial morbidity and mortality. At present, imaging of PCa has become increasingly important for staging, restaging, and treatment selection. Until recently, choline-based positron emission tomography/computed tomography (PET/CT) represented the state-of-the-art radionuclide imaging technique for these purposes. However, its application is limited to patients with high PSA levels and Gleason scores. Prostate-specific membrane antigen (PSMA) is a promising new target for specific imaging of PCa, because it is upregulated in the majority of PCa. Moreover, PSMA can serve as a target for therapeutic applications. Currently, several small-molecule PSMA ligands with excellent in vivo tumor targeting characteristics are being investigated for their potential in theranostic applications in PCa. Here, a review of the recent developments in PSMA-based diagnostic imaging and therapy in patients with PCa with radiolabeled PSMA ligands is provided.
\end{abstract}

Key words: PSMA, prostate cancer, PET, radionuclide imaging, theranostics

\section{Introduction}

Prostate cancer (PCa) is the most common type of cancer in men worldwide leading to substantial morbidity and mortality. At present, imaging of PCa is indicated for primary diagnosis, staging and restaging, as well as for the detection of (biochemical) recurrent disease. Currently, conventional imaging modalities, including ultrasound, bone scintigraphy, and computed tomography (CT) are used to detect primary and metastatic $\mathrm{PCa}$ for staging and risk stratification. Despite significant efforts, conventional imaging of PCa does not contribute to patient management as much as imaging performed in patients with other common cancers. Magnetic resonance imaging (MRI), particularly innovative methods such as diffusion-weighted MRI (DWI), or dynamic contrast-enhanced MRI (DCE-MRI), which allow func- tional assessment of the disease, are growingly important for imaging of PCa. However, these techniques do not allow tumor-specific imaging. While radionuclide imaging techniques such as $\left[{ }^{18} \mathrm{~F}\right]$-fluorodeoxyglucose (FDG) positron emission tomography (PET)/CT provide high sensitivity to detect tumor lesions for numerous malignancies, this technique is inadequate for (re)staging of $\mathrm{PCa}$, as a large fraction of PCa show limited [18F]-FDG uptake $[1,2]$.

Choline radiolabeled with ${ }^{11} \mathrm{C}$ or ${ }^{18} \mathrm{~F}$ represents a more suitable alternative to $\left.{ }^{18} \mathrm{~F}\right]-\mathrm{FDG}-\mathrm{PET} / \mathrm{CT}$ and is currently used in the clinics as PET tracer for (re)staging of PCa [3]. Choline is a key precursor in the biosynthesis of phosphatidylcholine, a major component of the cell membrane. Increased levels of 
total choline incorporation have been observed in several malignancies [4, 5]. While choline-based PET/CT can be used in PCa patients in particular settings, such as for the evaluation of high-risk patients with high PSA levels and Gleason scores, this method has limited sensitivity for initial staging of patients, lymph node detection, as well as for restaging of patients with biochemical recurrence with PSA $<2 \mathrm{ng} / \mathrm{ml}$ [6-10]. Due to the lack of sensitive imaging methods for $\mathrm{PCa}$, extensive research is focused on the development of new tracers that allow more sensitive and specific detection of PCa lesions with PET [11].

The prostate-specific membrane antigen (PSMA) is a type II integral membrane glycoprotein that was first detected on the human prostatic carcinoma cell line LNCaP [12]. PSMA was identified as a homologue of the protein N-acetyl-L-aspartyl-L-glutamate peptidase I (NAALADase I or folate hydrolase I), a protein which is active in the central nervous system, where it cleaves the neurotransmitter N-Acetyl-1aspartyl-l-glutamate (NAAG) into $\mathrm{N}$-acetylaspartate (NAA) and glutamate [13, 14]. In malignant tissue, PSMA has been suggested to be involved in angiogenesis, as increased PSMA expression was found to be expressed in the stroma adjacent to neovasculature of solid tumors [15]. Due to its selective overexpression in $90-100 \%$ of local PCa lesions, as well as in cancerous lymph nodes, and bone metastases [16-18], PSMA is a reliable tissue marker for PCa and is considered an ideal target for theranostic applications [14, 19-22].

Increased PSMA expression is correlated with an increase in tumor grade, pathological stage, aneuploidy, and biochemical recurrence. Most importantly, PSMA expression is upregulated when tumors become androgen-independent, showing upregulated PSMA expression after anti-androgen therapy in up to $100 \%$ of the cases [23]. This characteristic makes PSMA particularly valuable, since it has potential as an early indicator of tumor progression after androgen-deprivation therapy. PSMA expression was proven to be a prognostic factor for disease recurrence [24].

One of the first imaging probes specifically targeting PSMA was 111In-capromab pendetide (Prostascint $\left.{ }^{\circledR}\right)$, a ${ }^{111}$ In-labeled anti-PSMA antibody [25]. An important limitation of capromab pendetide is the fact that it binds to an intracellular domain of PSMA. Therefore, capromab pendetide either binds to viable tumor cells following internalization or to dying cells with disrupted cellular membranes. Because of the high non-specific uptake and the relatively poor tumor-to-background ratios, the application of ${ }^{111}$ In-capromab pendetide for imaging prostatic malignancies remained rather limited [26, 27].
Subsequently, high affinity antibodies directed against extracellular epitopes of PSMA have been developed, such as J415, J533, and J591 [28]. It was shown that ${ }^{111}$ In-J591 accurately targets bone and soft tissue metastatic PCa lesions [29] and that ${ }^{177}$ Lu-labeled J591 can be used safely in radioimmunotherapy (RIT) directed against micrometastatic PCa [30]. Major disadvantages limiting the use of radiolabeled monoclonal antibodies as theranostic radiopharmaceuticals are their relatively long circulatory half-life (3-4 days), poor tumor penetration, and low tumor-to-normal tissue ratios, especially at early time points. Small molecules, in contrast, exhibit rapid extravasation, rapid diffusion in the extravascular space, and faster blood clearance. This could result in high tumor-normal tissue contrast early after injection of the tracer.

In search for PSMA tracers with such favorable characteristics, modified forms of NAALAdase inhibitors, which were originally developed for possible neuroprotective effects in neurological disorders such as ALS [31], have been evaluated for their potential to diagnose and treat PCa. A series of preclinical studies evaluated the role of radiolabeled small-molecule PSMA inhibiting ligands for imaging of human PCa using various radionuclides such as ${ }^{11} \mathrm{C}$ [32], ${ }^{18} \mathrm{~F}$ [33], ${ }^{123} \mathrm{I}$ [34], ${ }^{99 \mathrm{~m} T \mathrm{c}}[34-36]$, and ${ }^{68} \mathrm{Ga}[37,38]$. The compounds used in these studies can be classified into three groups: (1) the urea-based compounds, (2) the glutamate phosphoramidates and (3) the 2-(phosphinylmethyl) pentanedioic acids [21] (figure 1). Overall, the PSMA ligands tested in these preclinical studies showed high tumor uptake peaking at 0.5 $-1 \mathrm{~h}$ in mice with PSMA-expressing tumors. At earlier time points, the contrast was impaired due to high blood levels. For imaging purposes, this time frame matches best with radionuclides with half-lives of 1-2 h (i.e. ${ }^{68} \mathrm{Ga}$ or ${ }^{18} \mathrm{~F}$ ). In some of these preclinical studies, remarkable changes in affinity and tumor uptake were observed upon changes in the radiolabel, chelator, and linker. First of all, it has been suggested that a spacer is required between the PSMA binding motif and the chelator. Chen et al. have compared PSMA ligands with different linker lengths and showed that an increased linker length enhanced the affinity for PSMA and increased tumor uptake [39]. The binding site for the glutamate-urea-lysine sequence is linked to a tunnel-like region $(\sim 20 \AA)$ and by using a long linker, bulky chelated metals are situated outside the active site and will not interfere with binding to the active site of PSMA [39, 40]. Second, Huang et al. showed that strategic placement of (multiple) negative charges in the linker region significantly reduced the retention in non-target tissue, without reducing the accumulation in the tumor [41]. Finally, the in- 
troduction of hydrophobic naphtyl groups significantly increased tumor uptake, while the retention in the kidney was reduced [42]. Based on these preclinical aspects, several clinical studies evaluating PSMA ligands have been performed. In this review, the clinical status on PSMA ligands for theranostic applications in PCa will be discussed.

\section{Diagnostic Imaging Using Radiolabeled PSMA Ligands in Prostate Cancer}

Since 2012, the number of clinical studies using urea-based PSMA ligands, such as 123/124/131 I-
MIP-1072/-1095 [43], 99mTc-MIP-1404/-1405 [44], ${ }^{68} \mathrm{Ga}-\mathrm{HBED}-\mathrm{PSMA}$, [18F]-DCFBC [45], and [18F]-DCFPyl, exponentially increased [43, 45-49] (figure 2). Among these agents, the ${ }^{68} \mathrm{Ga}-$ and ${ }^{18} \mathrm{~F}$-labeled compounds have attracted the most attention, as these compounds can be used for PET/CT imaging. However, the availability of ${ }^{123} \mathrm{I}$ or ${ }^{99 \mathrm{mTc}} \mathrm{Tl}-$ lows SPECT/CT imaging in centers without facilities for PET. An overview on clinical studies using radiolabeled PSMA ligands for PCa diagnosis is provided in table 1.

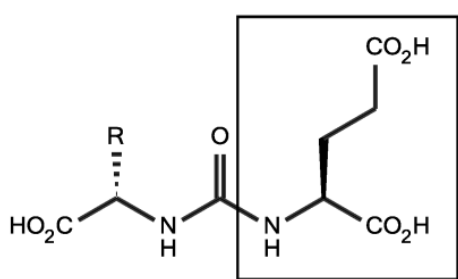

1

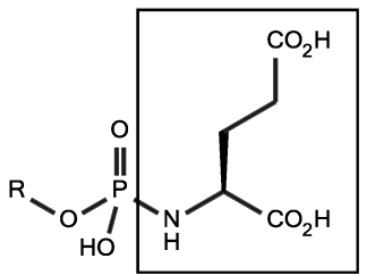

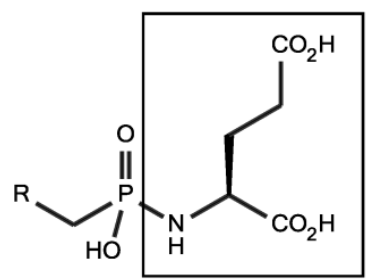

Figure 1: Classification of small molecule PSMA inhibitors used in (pre-)clinical studies for PCa. 1: urea-based glutamate heterodimers, 2: phosphoramidates, 3: 2-(phosphinylmethyl) pentanedioic acids

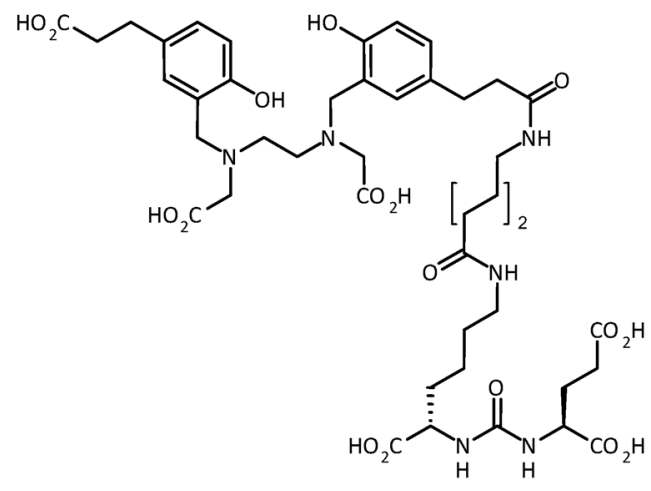

Glu-NH-CO-NH-Lys(Ahx)-HBED-CC

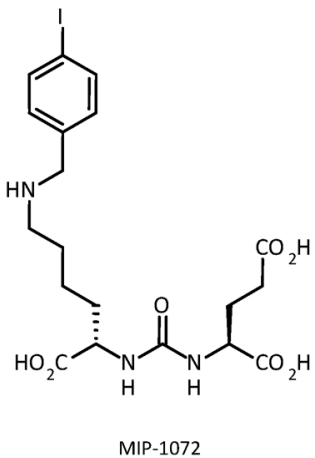

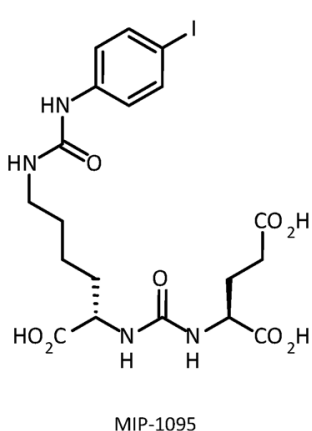

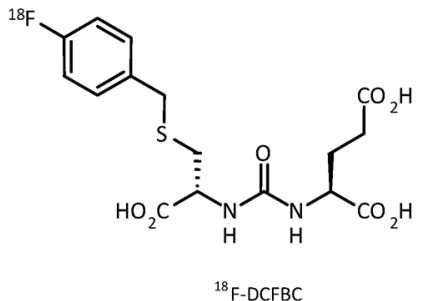

Figure 2: Small-molecule PSMA ligands currently being investigated for PCa imaging in clinical settings. All possess the characteristic glu-urea-lys core. 
Table 1: Overview on diagnostic clinical studies using radiolabeled PSMA ligands for PCa diagnosis and therapy.

\begin{tabular}{|c|c|c|c|c|c|c|c|c|c|}
\hline PSMA ligand & Study & Year & $\begin{array}{l}\text { Ra- } \\
\text { dio-nuc } \\
\text { lide }\end{array}$ & $\begin{array}{l}\text { Patient } \\
\text { no }\end{array}$ & GSC & $\begin{array}{l}\text { Medi- } \\
\text { an PSA } \\
\text { Level } \\
(\mathrm{ng} / \mathrm{ml}) \\
\end{array}$ & $\begin{array}{l}\text { Admin- } \\
\text { istered } \\
\text { dose } \\
(\mathrm{MBq}) \\
\end{array}$ & $\begin{array}{l}\text { Scanning } \\
\text { time points }\end{array}$ & $\begin{array}{l}\text { Organs that received the } \\
\text { highest dose }\end{array}$ \\
\hline $\begin{array}{l}\text { MIP-1072, } \\
\text { MIP-1095 }\end{array}$ & Barrett et al. & 2013 & $\mathrm{I}-123$ & 7 & $\begin{array}{l}\text { not pro- } \\
\text { vided }\end{array}$ & $\begin{array}{l}121 \\
\text { (mean) }\end{array}$ & $\begin{array}{l}370 \\
\text { (mean) }\end{array}$ & $\begin{array}{l}4 \mathrm{~h} \text { and } 24 \mathrm{~h} \\
\text { p.i. } \\
(\mathrm{SPECT} / \mathrm{CT})\end{array}$ & $\begin{array}{l}\text { 123I-MIP-1072: } \\
\text { salivary glands: } 0.058 \text { urinary } \\
\text { bladder wall: } 0.092 \\
\text { kidneys: } 0.054 \\
\text { 123I-MIP-1095: } \\
\text { the salivary glands: } 0.160 \\
\text { kidneys: } 0.110 \\
\text { thyroid: } 0.100 \\
\text { (mGy/MBq) }\end{array}$ \\
\hline MIP-1095 & Zechmann et al. & 2014 & $\begin{array}{l}\mathrm{I}-124 / \\
\mathrm{I}-131\end{array}$ & 16 & $\begin{array}{l}7 \\
\text { (median) }\end{array}$ & 110.5 & $\begin{array}{l}67.4 \\
\text { (mean) }\end{array}$ & $\begin{array}{l}\text { 1, 4, 24, } 48,72 \\
\text { h p.i. } \\
(\mathrm{PET} / \mathrm{CT})\end{array}$ & $\begin{array}{l}\text { salivary glands: } 3.76 \pm 2.29 \\
\text { liver: } 1.66 \pm 0.61 \\
\text { kidneys: } 1.39 \pm 0.56 \\
(\mathrm{mSv} / \mathrm{MBq})\end{array}$ \\
\hline $\begin{array}{l}\text { MIP-1404 } \\
\text { MIP-1405 }\end{array}$ & $\begin{array}{l}\text { Vallabhajosula et } \\
\text { al. }\end{array}$ & 2014 & Tc-99m & 6 & $\begin{array}{l}\text { not pro- } \\
\text { vided }\end{array}$ & $\begin{array}{l}15.8 \\
\text { (mean) }\end{array}$ & $\begin{array}{l}740 \pm \\
111 \mathrm{MBq}\end{array}$ & $\begin{array}{l}\text { 3-5 h p.i. } \\
\text { (SPECT/CT) }\end{array}$ & $\begin{array}{l}\text { 99mTc-MIP-1404: } \\
\text { kidneys: } 0.0733 \\
\text { salivary glands: } 0.0524 \\
\text { spleen: } 0.0218 \\
\text { 99mTc-MIP-1405: } \\
\text { urinary bladder wall: } 0.0434 \\
\text { kidneys: } 0.0363 \\
\text { salivary glands: } 0.0301 \\
\text { (mGy/MBq) }\end{array}$ \\
\hline $\begin{array}{l}\text { Glu-NH-CO-N } \\
\text { H-Lys(Ahx)-HB } \\
\text { ED-CC }\end{array}$ & $\begin{array}{l}\text { Afshar-Oromieh } \\
\text { et al. }\end{array}$ & 2013 & Ga-68 & 37 & $\begin{array}{l}7 \\
\text { (median) }\end{array}$ & 3.3 & $\begin{array}{l}121 \\
\text { (median) }\end{array}$ & $\begin{array}{l}1 \text { and } 3 \mathrm{~h} \text { p.i. } \\
\text { (PET/CT) }\end{array}$ & $\begin{array}{l}\text { intense tracer uptake: } \\
\text { kidneys and salivary glands, } \\
\text { moderate tracer uptake: } \\
\text { lacrimal glands, liver, spleen } \\
\text { and in small and large bowel } \\
\text { (based on SUV mean and SU- } \\
\mathrm{V}_{\max } \text { ) }\end{array}$ \\
\hline $\begin{array}{l}\text { Glu-NH-CO-N } \\
\text { H-Lys(Ahx)-HB } \\
\text { ED-CC }\end{array}$ & $\begin{array}{l}\text { Afshar-Oromieh } \\
\text { et al. }\end{array}$ & 2014 & Ga-68 & 20 & $\begin{array}{l}7.6 \\
\text { (mean) }\end{array}$ & 2.62 & $\begin{array}{l}149 \\
\text { (median) }\end{array}$ & $\begin{array}{l}1 \text { h p.i. } \\
\text { (PET/CT) } \\
3 \text { h p.i. } \\
\text { (PET/MRI) }\end{array}$ & \\
\hline $\begin{array}{l}\text { Glu-NH-CO-N } \\
\text { H-Lys(Ahx)-HB } \\
\text { ED-CC }\end{array}$ & $\begin{array}{l}\text { Afshar-Oromieh } \\
\text { et al. }\end{array}$ & 2014 & Ga-68 & 37 & $\begin{array}{l}7.4 \\
\text { (mean) }\end{array}$ & 11.1 & $\begin{array}{l}132 \\
\text { (median) }\end{array}$ & $\begin{array}{l}1 \mathrm{~h} \text { p.i. } \\
\text { (PET/CT) }\end{array}$ & \\
\hline $\begin{array}{l}\text { Glu-NH-CO-N } \\
\text { H-Lys(Ahx)-HB } \\
\text { ED-CC }\end{array}$ & $\begin{array}{l}\text { Afshar-Oromieh } \\
\text { et al. }\end{array}$ & 2015 & Ga-68 & 319 & $\begin{array}{l}7.5 \\
\text { (mean) }\end{array}$ & 161 & $\begin{array}{l}154 \\
\text { (median) }\end{array}$ & $\begin{array}{l}45-75 \text { min. p.i. } \\
\text { (PET/CT) }\end{array}$ & \\
\hline $\begin{array}{l}\text { Glu-NH-CO-N } \\
\text { H-Lys(Ahx)-HB } \\
\text { ED-CC }\end{array}$ & Eiber et al. & 2015 & Ga-68 & 248 & $\begin{array}{l}7 \\
\text { (median) }\end{array}$ & 1.99 & $\begin{array}{l}155.5 \\
\text { (mean) }\end{array}$ & $\begin{array}{l}\text { 47-61 min. p.i. } \\
\text { (PET/CT) }\end{array}$ & \\
\hline DCFBC & Cho et al. & 2012 & F-18 & 5 & $\begin{array}{l}8.2 \\
\text { (mean) }\end{array}$ & 10.5 & $\begin{array}{l}370 \\
\text { (mean) }\end{array}$ & $\begin{array}{l}2 \text { h p.i. } \\
\text { (PET/CT) }\end{array}$ & $\begin{array}{l}\text { urinary bladder wall: } 0.0324 \\
\text { stomach: } 0.0302 \\
\text { heart wall: } 0.0292 \\
\text { kidneys: } 0.0284 \\
\text { (mGy/MBq) }\end{array}$ \\
\hline DCFPyl & Szabo et al2 & 2015 & F-18 & 9 & $\begin{array}{l}8.2 \\
\text { (mean) }\end{array}$ & 30.6 & $\begin{array}{l}320.6 \\
\text { (mean) }\end{array}$ & $\begin{array}{l}\text { h p.i. } \\
\text { (PET/CT) }\end{array}$ & $\begin{array}{l}\text { kidneys: } 0.0945 \\
\text { urinary bladder wall: } 0.0864 \\
\text { submandibular glands: } 0.0387 \\
(\mathrm{mGy} / \mathrm{MBq})\end{array}$ \\
\hline
\end{tabular}

\section{SPECT/CT imaging with I-123/l-124-labeled PSMA ligands}

Barrett et al. reported the first in man study with the two radioiodinated glutamate-urea-lysine PSMA inhibitors 123I-MIP-1072 [(S)-2-(3-((S)-1-carboxy-5-(4iodobenzylamino)pentyl)ureido) pentanedioic acid] and 123I-MIP-1095 [(S)-2-(3-((S)-1-carboxy-5-(3-(4iodophenyl)ureido)pentyl)ureido) pentanedioic acid] in patients with PCa [43]. ${ }^{123}$ I-MIP-1072 cleared from the body more rapidly than 123I-MIP-1095: $28 \%$ of 123I-MIP-1072 versus 2\% of 123I-MIP-1095 cleared within the first 6 hours. The effect has been attributed to the higher lipophilicity of ${ }^{123}$ I-MIP-1095 [43]. The estimated effective dose was $0.022 \mathrm{mSv} / \mathrm{MBq}$ and $0.032 \mathrm{mSv} / \mathrm{MBq}$ for ${ }^{123} \mathrm{I}-\mathrm{MIP}-1072$ and ${ }^{123} \mathrm{I}-\mathrm{MIP}-1095$, respectively. In animals models, the tumor uptake of MIP-1095 was higher compared with MIP-1072, which was attributed to the 5-fold higher affinity of MIP-1095 over MIP-1072 $\left(\mathrm{K}_{\mathrm{d}}=0.81 \pm 0.39\right.$ and $3.8 \pm 1.3$ $\mathrm{nM}$, respectively). This might be a result of additional hydrophobic interactions of the tracer with sites outside of the PSMA binding pocket [50]. For ${ }^{123}$ I-MIP-1072, the organs receiving the highest radiation dose were the salivary glands $(0.058 \mathrm{mGy} / \mathrm{MBq})$, urinary bladder wall $(0.092 \mathrm{mGy} / \mathrm{MBq})$ and kidneys 
(0.054 mGy/MBq), while for ${ }^{123}$ I-MIP-1095, these were the salivary glands $(0.160 \mathrm{mGy} / \mathrm{MBq})$, kidneys $(0.110$ $\mathrm{mGy} / \mathrm{MBq}$ ) and thyroid (0.100 mGy/MBq). The uptake in the kidneys and the salivary glands is receptor mediated, as these organs express significant levels of PSMA [22]. In six patients with metastatic PCa, lesions visible with SPECT/CT imaging correlated with the radiologic evidence of metastatic disease. This study demonstrated that 123I-MIP-1072 and 123I-MIP-1095 SPECT/CT are suitable tracers for detection of tumor lesions in the prostate gland, lymph nodes, and bones.

\section{SPECT/CT imaging with Tc-99m-labeled PSMA ligands}

Because ${ }^{99 \mathrm{~m} T \mathrm{c}}$ is the preferred radionuclide for developing SPECT radiopharmaceuticals, 2 high-affinity small-molecule PSMA inhibitors derived from glutamate-urea-glutamate or glutamate-urea-lysine pharmacophores, MIP-1404 and MIP-1405, chelated with single-amino-acid chelators (SAAC), were developed, which can be labeled with ${ }^{99 \mathrm{~m} T \mathrm{~T}}$ based on tricarbonyl chemistry [36]. The SAACs allow facile labeling with ${ }^{99 \mathrm{~m} T c}$ at room temperature, have robust complex stability, and were designed to minimize hepatobiliary uptake [51]. Preclinical studies showed high tumor uptake and tumor-to-blood ratios early after injection of 99mTc-MIP-1404 and 99mTc-MIP-1405. Vallabhajosula and colleagues evaluated the role of these tracers for detection of PCa lesions in 6 patients with radiographic evidence of metastatic disease [44]. Both 99mTc-MIP-1404 and 99mTc-MIP-1405 cleared rapidly from the circulation, with 99mTc-MIP-1404 demonstrating significantly lower urinary activity (7\%) than 99mTc-MIP-1405 $(26 \%)$. Both agents showed persistent uptake in the salivary, lacrimal, and parotid glands and rapid localization in bone and lymph node lesions as early as $1 \mathrm{~h}$ p.i.. Tracer uptake in salivary and lacrimal glands most likely is due to PSMA expression within these tissues [14, 48, 52]. SPECT images with excellent tumor-to-background contrast were obtained: tumor-to-background ratios ranging from 3:1 at $4 \mathrm{~h}$ p.i. to $9: 1$ at $20 \mathrm{~h}$ p.i.. More tumor lesions were visualized with 99mTc-MIP-1404 and 99mTc-MIP-1405 than with conventional bone scans. Overall, this study shows that PSMA ligands are feasible for ${ }^{99 \mathrm{mTc}-S P E C T / C T}$ based detection of PCa lesions.

\section{PET/CT imaging with Ga-68-labeled PSMA ligands}

During the past few years, the application of ${ }^{68} \mathrm{Ga}$-labeled peptides has attracted considerable interest for cancer imaging due to the physical characteristics of ${ }^{68} \mathrm{Ga}\left(\mathrm{t}^{1} / 2=68 \mathrm{~min}, \beta^{+}=1899 \mathrm{keV}\right)$ [53] and the availability of reliable GMP-compliant ${ }^{68} \mathrm{Ge} /{ }^{68} \mathrm{Ga}$ generators. Moreover, the half-life of ${ }^{68} \mathrm{Ga}$ matches the pharmacokinetics of the small PSMA inhibiting peptides.

One of the first PSMA inhibitors available for labeling with ${ }^{68} \mathrm{Ga}$ and PET imaging of PCa were 1,4,7,10-Tetraazacyclododecane-1,4,7,10-tetraacetic acid (DOTA)-conjugated urea-based PSMA inhibitors, developed and tested preclinically by Banerjee et al. [37]. In their animal study, PSMA-specific tumor imaging, with moderate tumor uptake (3.29 $\pm 0.77 \%$ ID/g) and high tumor-to-blood (22:1) ratios at $2 \mathrm{~h}$ p.i., was obtained in PSMA-expressing tumors $\left(\mathrm{K}_{\mathrm{i}} 1.2 \mathrm{nM}\right)$. Tumor uptake in PSMA-negative tumors was only $0.18 \pm 0.03 \% \mathrm{ID} / \mathrm{g}$ at $2 \mathrm{~h}$ p.i.. Eder et al. prepared the ${ }^{68} \mathrm{Ga}$-labeled PSMA inhibitor Glu-NH-CO-NHLys(Ahx)-HBED-CC using the chelator N,N'-bis[2-hydroxy-5-(carboxyethyl)-benzyl]ethylene diamineN, $\mathrm{N}^{\prime}$-diacetic acid (HBED-CC). Potentially, HBED is a more attractive chelator for ${ }^{68} \mathrm{Ga}$ than DOTA as it forms a more thermodynamically stable complex with ${ }^{68} \mathrm{Ga}$, even at room temperature [54]. Eder et al. compared Glu-NH-CO-NHLys(Ahx)$\left.\begin{array}{llllll}H B E D-C C & \left(\mathrm{~K}_{\mathrm{i}}\right. & 12.0 & \pm & 2.8 & \mathrm{nM}\end{array}\right)$ to Glu-NH-CO-NH-Lys-DOTA $\left(\mathrm{K}_{\mathrm{i}} 37.6 \pm 14.3 \mathrm{nM}\right)$ and demonstrated that the HBED-CC conjugated compound had more favorable properties for PCa imaging than the DOTA analogue [55]. ${ }^{68} \mathrm{Ga}$-labeled Glu-NH-CO-NH-Lys(Ahx)-HBED-CC showed fast blood clearance, relatively low liver uptake, and high specific uptake in PSMA-expressing tissues and tumor (tumor uptake $7.7 \pm 1.5 \% \mathrm{ID} / \mathrm{g}$ for the HBED-CC-conjugate, which was 2.6-fold higher compared to the DOTA compound). In addition, liver uptake of the HBED-CC conjugated ligand was 5.7-fold lower.

Based on the promising preclinical results, Afshar-Oromieh et al. investigated the role of the ${ }^{68} \mathrm{Ga}$-labeled PSMA ligand Glu-NH-CO-NHLys(Ahx)-HBED-CC ( $\left.{ }^{68} \mathrm{Ga}-\mathrm{HBED}-\mathrm{CC}-\mathrm{PSMA}\right)$ in a cohort of 37 patients (median PSA: $3.3 \mathrm{ng} / \mathrm{ml}$, range: 0.01-148 ng/ml, median GSC: 7.0) [48]. Patients received $121.0 \mathrm{MBq}$ (range 52 - $212 \mathrm{MBq}$ ) of ${ }^{68} \mathrm{Ga}-\mathrm{HBED}-\mathrm{CC}-\mathrm{PSMA}$. In $84 \%$ of the patients, PCa lesions were identified. PCa lesions were found in $60 \%$ of the patients with PSA levels $<2.2 \mathrm{ng} / \mathrm{ml}$, while at PSA levels of $>2.2 \mathrm{ng} / \mathrm{ml}$, PCa lesions were found in all patients. Thus even at relatively low blood PSA levels, ${ }^{6}$ Ga-HBED-CC-PSMA-PET/CT identified lesions with high tumor-to-background ratios [48]. In vivo, tumor uptake of ${ }^{68} \mathrm{Ga}-H B E D-C C-P S M A$ was stable between $1 \mathrm{~h}$ and $3 \mathrm{~h}$, while in normal tissue uptake slightly decreased between 1 and $3 \mathrm{~h}$. As a result, late scans exhibited higher tumor-to-background ratios, which might be useful when lesions remain unclear in an early scan. Besides 
tumor uptake, high tracer uptake was observed in kidneys, salivary glands, spleen and liver [48]. An example of a PET/CT image of a patient with recurrent $\mathrm{PCa}$ who underwent ${ }^{68} \mathrm{Ga}-\mathrm{HBED}-\mathrm{CC}-\mathrm{PSMA}$ PET/CT (1 h p.i.) is presented in figure 3.

In a subsequent study, ${ }^{68} \mathrm{Ga}-H B E D-C C-P S M A$ PET/CT $(150 \mathrm{MBq})$ was compared with ${ }^{68} \mathrm{Ga}-\mathrm{HBED}-\mathrm{CC}-\mathrm{PSMA}$ PET/MRI to evaluate whether PET/MRI could have additional value in the detection of PCa lesions [49]. Twenty patients (median PSA: $2.62 \mathrm{ng} / \mathrm{ml}$, range: 0.51-73.60) were scanned with PET/CT $1 \mathrm{~h}$ p.i. and PET/MRI 3 h p.i.. Out of the 75 lesions which were characterized further, four lesions unclear in PET/CT could be established being PCa lesions in PET/MRI. Pathological lesions visible on PET often correlated with signals on MRI, offering a considerable advantage for PET/MR imaging. Overall, PCa was detected more easily and more ac-

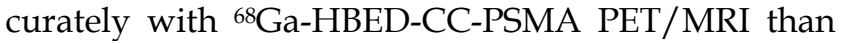
with PET/CT. In figure 4, PET/CT and PET/MRI images of one patient are displayed, demonstrating that a suspect lymph node could be detected with ${ }^{68} \mathrm{Ga}-\mathrm{HBED}-\mathrm{CC}-\mathrm{PSMA}$ PET/MRI but did not show increased PSMA ligand uptake in PET/CT. A potential disadvantage of PET/MRI imaging was the appearance of halo artefacts around the bladder and kidneys, resulting in a reduced PET signal, and potentially making lesions in their vicinity undetectable (figure 5) [49].
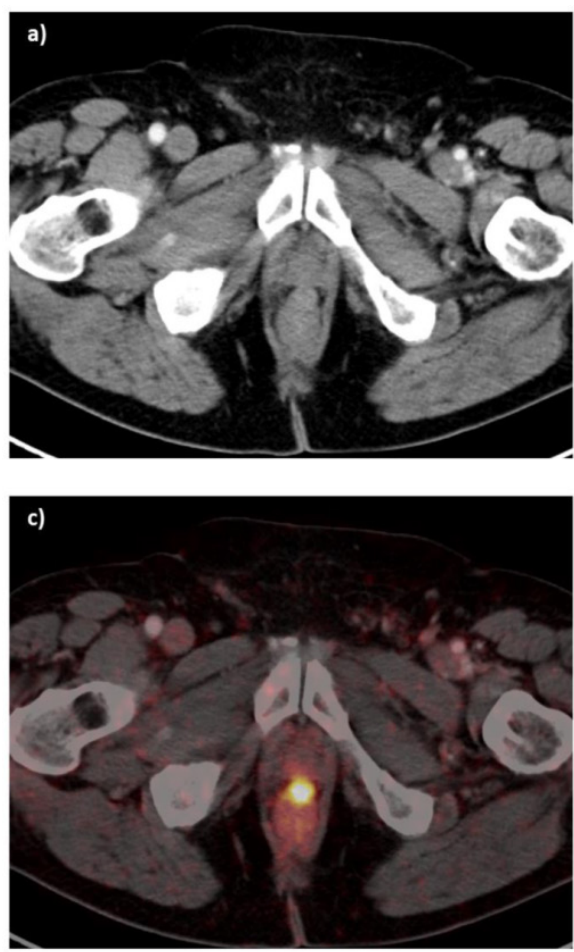

As until recently, choline based PET/CT was the leading radionuclide imaging method for detection/staging of $\mathrm{PCa}$, Afshar-Oromieh et al. directly compared ${ }^{68} \mathrm{Ga}-H B E D-C C-P S M A$ PET/CT with $\left[{ }^{18} \mathrm{~F}\right]$-Fluoromethylcholine $(\mathrm{FCH}) \mathrm{PET} / \mathrm{CT}$ to evaluate which technique is superior in the detection of $\mathrm{PCa}$ lesions [47]. In a restaging setting, 37 patients (mean PSA: $11.1 \mathrm{ng} / \mathrm{ml}$, range: $0.01-116 \mathrm{ng} / \mathrm{ml}$, mean GSC: 7.4) were scanned with PET/CT at $1 \mathrm{~h}$ p.i.. At least one $\mathrm{PCa}$ lesion was detected with ${ }^{68} \mathrm{Ga}-\mathrm{HBED}-\mathrm{CC}-\mathrm{PSMA}-\mathrm{PET} / \mathrm{CT}$ in $87 \%$ of the patients, whereas this was the case in only $70 \%$ of the patients when $\left[{ }^{18} \mathrm{~F}\right]-\mathrm{FCH}$ was used as a tracer. At PSA values >2.82 ng/ml, ${ }^{68} \mathrm{Ga}-H B E D-C C-P S M A$ could detect at least one lesion in each patient, for choline this was the case in $91 \%$ of the patients. At PSA levels $<2.82 \mathrm{ng} / \mathrm{ml}$ at least one lesion could be detect in $69 \%$ and $44 \%$ of the patients using ${ }^{68} \mathrm{Ga}-\mathrm{HBED}-\mathrm{CC}-\mathrm{PSMA}$ and $\left[{ }^{18} \mathrm{~F}\right]-\mathrm{FCH}$, respectively. Most importantly, all lesions visible in $\left.{ }^{18} \mathrm{~F}\right]-\mathrm{FCH}-\mathrm{PET} / \mathrm{CT}$ were also visible using ${ }^{68} \mathrm{Ga}-H B E D-C C-P S M A-P E T / C T$. Among the 78 lesions identified using ${ }^{68} \mathrm{Ga}-\mathrm{HBED}-\mathrm{CC}-\mathrm{PSMA}-$ PET/CT, 40 were defined as lymph node metastases, 23 as bone metastases, 10 as local relapses, and 5 as soft tissue metastases. The maximum standardized uptake values $\left(\mathrm{SUV}_{\max }\right)$ were clearly $(>10 \%)$ higher in ${ }^{68} \mathrm{Ga}-H B E D-C C-P S M A-P E T / C T$ compared to $\left[{ }^{18} \mathrm{~F}\right]-\mathrm{FCH}-\mathrm{PET} / \mathrm{CT}$ in 62 of 78 lesions, lower in 12 and equal in 4.

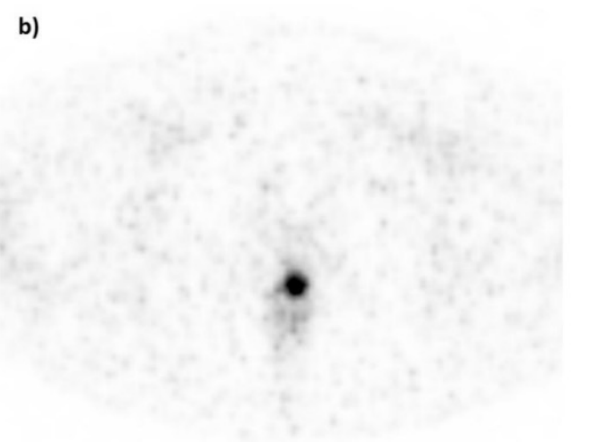

d)

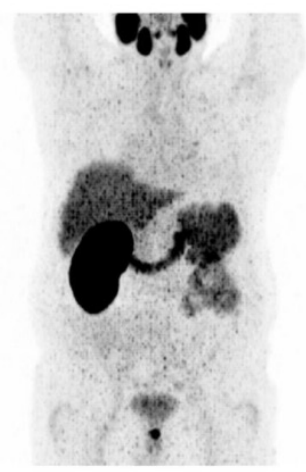

Figure 3: ${ }^{68} \mathrm{Ga}$-HBED-CC-PSMA PET/CT image of a patient with locally recurrent PCa (PSA $3.7 \mathrm{ng} / \mathrm{ml}$ ) after radical prostatectomy $\left(\mathrm{SUV} \mathrm{V}_{\max } 12.4\right)$ who received $140 \mathrm{MBq}$ of the ${ }^{68} \mathrm{Ga}$-labeled tracer molecule and was scanned at $1 \mathrm{~h}$ p.i.; a) CT image, b) PET image, c) PET/CT fusion image, d) MIP. 

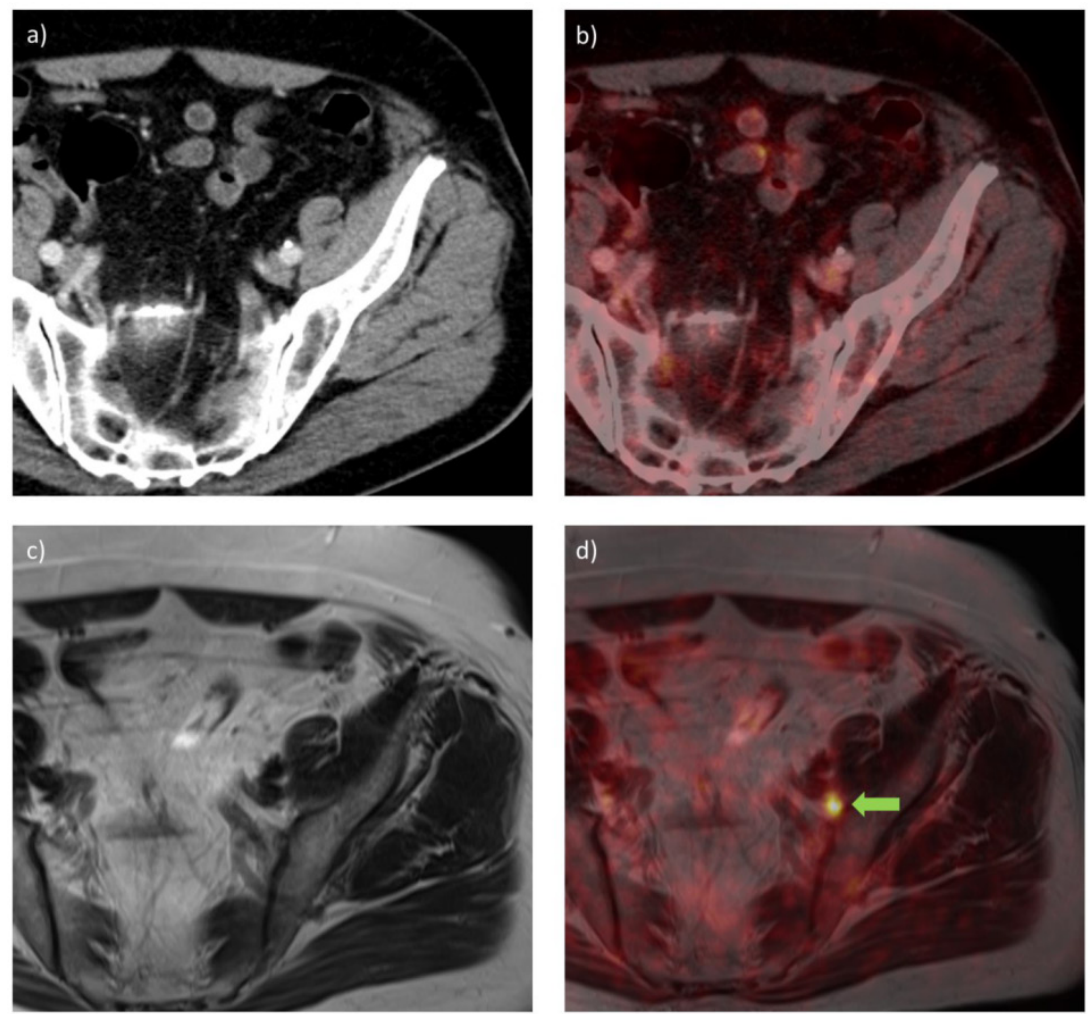

Figure 4: ${ }^{68} \mathrm{Ga}$-HBED-CC-PSMA PET/CT (a, b) and PET/MRI (c, d) images of a patient with PCa with recurrent disease in an inguinal lymph node (PSA 0.9 $\mathrm{ng} / \mathrm{ml}$ ) after radical prostatectomy, scanned at $1 \mathrm{~h}$ and $3 \mathrm{~h}$ p.i., using PET/CT and PET/MRI, respectively. a) CT image, b) PET/CT fusion image, c) MR image (T2-weighted with contrast medium and turbo spin echo), d) PET/MRI fusion image. A metastatic lymph node is visible in the PET/MRI fusion image (green arrow), while the same lesion could not be visualized with PET/CT.

a)

b)
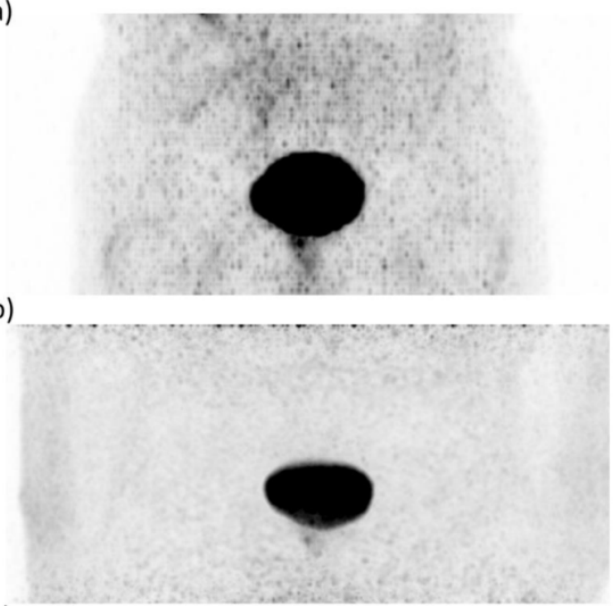

c)

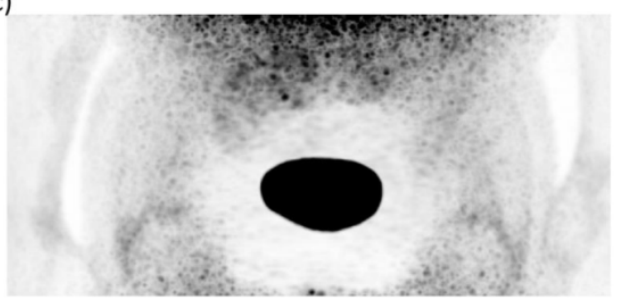

Figure 5: ${ }^{68} \mathrm{Ga}-\mathrm{HBED}-\mathrm{CC}-\mathrm{PSMA}$ PET images of a patient with PCa after radical prostatectomy with recurrent disease in an inguinal lymph node. While the scatter corrected PET image from the PET/CT system (a) and the not scatter corrected PET image from the PET/MRI system (b) show no artefact, the scatter corrected PET image from the PET/MRI system shows an extensively reduced signal around the urinary bladder (b), previously described as 'halo' artefact [49].
Tumor-to-background ratios obtained with ${ }^{68} \mathrm{Ga}-H B E D-C C-P S M A$ were higher in 74 out of 78 lesions. In seven patients, these lesions were confirmed to be PCa by biopsy or surgery. No false-positives were found. Overall, this study suggests a significantly improved sensitivity of ${ }^{68} \mathrm{Ga}-H B E D-C C-P S M A-P E T / C T$ compared with $\left[{ }^{18} \mathrm{~F}\right]-\mathrm{FCH}-\mathrm{PET} / \mathrm{CT}$, especially at low PSA $(<2.2$ $\mathrm{ng} / \mathrm{ml}$ ) [47]. In a similar study, Morigi et al. compared the tumor lesion detection rate of that of $\left[{ }^{18} \mathrm{~F}\right]-\mathrm{FCH}-\mathrm{PET} / \mathrm{CT}$ to that of ${ }^{68} \mathrm{Ga}-\mathrm{HBED}-\mathrm{CC}-$ PSMA-PET/CT in 38 patients with biochemically recurrent $\mathrm{PCa}$ [56]. Of the 26 patients that had a positive scan, $54 \%(14 / 26)$ were positive on PSMA alone, $42 \%$ $(11 / 26)$ on both FCH and PSMA and only $4 \%(1 / 26)$ on FCH alone. At PSA levels of $<0.5 \mathrm{ng} / \mathrm{ml}$, PSMA detection rate was $50 \%$ vs. $12.5 \%$ for $\mathrm{FCH}$. At serum PSA levels between $0.5-2.0 \mathrm{ng} / \mathrm{ml}$, the detection rate was $69 \%$ for PSMA and $31 \%$ for FCH, and at PSA $>2.0$, the detection rate was $86 \%$ for PSMA and $57 \%$ for FCH. It was shown that PSMA detected more lesions than FCH (59 and 29, respectively). Overall, these studies suggest that ${ }^{68} \mathrm{Ga}-H B E D-C C-P S M A-$ $\mathrm{PET} / \mathrm{CT}$ is superior in the tumor lesion detection as compared to $\left[{ }^{18} \mathrm{~F}\right]-\mathrm{FCH}-\mathrm{PET} / \mathrm{CT}$.

After proof-of-principle was provided that ${ }^{68} \mathrm{Ga}-H B E D-C C-P S M A-P E T / C T$ is feasible for the de- 
tection of PCa lesions, Afshar-Oromieh et al. retrospectively investigated the diagnostic value of ${ }^{68} \mathrm{Ga}-\mathrm{HBED}-\mathrm{CC}-\mathrm{PSMA}-\mathrm{PET} / \mathrm{CT}$ in a larger group of patients $(\mathrm{n}=319)$ with PCa [57]. ${ }^{68} \mathrm{Ga}-\mathrm{HBED}-\mathrm{CC}-\mathrm{PSMA}$ PET/CT at $1 \mathrm{~h}$ p.i. detected PCa in $83 \%$ of the patients suspected recurrent PCa (264 of 319 patients). In addition, the tracer is highly specific for PCa: histological analysis demonstrated that tracer accumulation in tumor lesions correlated with manifestations of PCa in virtually all cases without false-positive lesions. Eiber et al. reported the diagnostic accuracy of

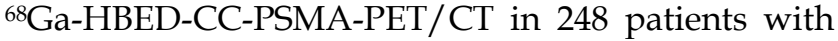
biochemical recurrence after radical prostatectomy. In this study, 222 patients $(89.5 \%)$ showed pathological findings in ${ }^{68} \mathrm{Ga}-H B E D-C C-P S M A-P E T / C T$, which implies a false-negative rate of $10.5 \%$ for ${ }^{68} \mathrm{Ga}-H B E D-C C-P S M A-P E T / C T$ imaging as in the case of biochemical recurrence by definition recurring tumor must be present. The detection rates were $96.8 \%, 93 \%, 72.7 \%$, and $57.9 \%$ in patients with serum PSA-levels of $\geq 2.1,<2.0-1.0,<1.0-0.5$, and $<0.5-0.2$

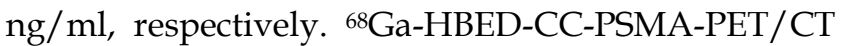
showed substantially higher detection rates compared to reports in the literature stating detection rates between $34 \%$ and $88 \%$ for ${ }^{11} \mathrm{C}$-Choline, $43-79 \%$ for ${ }^{18} \mathrm{~F}-\mathrm{Choline}$ and $59-80 \%$ for ${ }^{11} \mathrm{C}$-Acetate $[58,59]$. Most importantly, a high number of positive findings $(11 / 19,57.9 \%)$ in the clinically important range of low PSA-values $(<0.5 \mathrm{ng} / \mathrm{ml})$ was identified [58]. While it has been shown that the diagnostic value of ${ }^{68} \mathrm{Ga}-\mathrm{HBED}-\mathrm{CC}-\mathrm{PSMA}-\mathrm{PET} / \mathrm{CT}$ in patients with PCa is relatively high, even in patients with low PSA serum levels and compared to other tracers such as $\left[{ }^{18} \mathrm{~F}\right]-\mathrm{FCH}$, approximately $40 \%$ of the patients with PSA levels of $<0.5 \mathrm{ng} / \mathrm{ml}$ showed false-negative ${ }^{68} \mathrm{Ga}-H B E D-C C-P S M A-P E T / C T$ results [57]. Therefore, Ceci et al. evaluated, which factors are associated with the ${ }^{68} \mathrm{Ga}-\mathrm{HBED}-\mathrm{CC}-\mathrm{PSMA}-\mathrm{PET} / \mathrm{CT}$ tumor lesion detection rate [60]. In this study, 70 patients with recurrent PCa which underwent ${ }^{68} \mathrm{Ga}-\mathrm{HBED}-\mathrm{CC}-$ PSMA-PET/CT and were retrospectively evaluated regarding their previous therapies, serum PSA levels, PSA doubling times and PSA velocity. A serum PSA level of $0.83 \mathrm{ng} / \mathrm{mL}$ and a PSA doubling time of 6.5 months were found to be valuable cut-off values for predicting with high probability a positive or negative scan result. In particular, $85 \%$ of patients with short PSA doubling times who were candidates for radiotherapy to the prostate bed (early phase of biochemical recurrence with low PSA levels) showed positive findings on PET/CT, while only $18.7 \%$ of patients with similar low PSA levels, but with long PSA doubling time were PET-positive. These preliminary results may contribute to a better selection of patients who potentially apply for PSMA PET/CT.
The clinical studies so far convincingly demonstrate that ${ }^{68} \mathrm{Ga}-H B E D-C C-P S M A$ is a promising tracer for detection of (metastatic) PCa cancer lesions, even in patients with relatively low PSA levels, which could lead to substantial improvements in clinical care, since tumor lesions can be detected in early stages of the disease (recurrence). However, the experience with ${ }^{68} \mathrm{Ga}-H B E D-C C-P S M A-P E T / C T$ in clinical practice is still limited and several pitfalls have become apparent. Krohn et al. reported the seemingly pathological uptake of ${ }^{68} \mathrm{Ga}-H B E D-C C-P S M A$ in coeliac ganglia [61]. In 76 of the 85 patients $(89.4 \%)$ at least one ganglion was observed. One should be aware of the uptake in coeliac ganglia when interpreting the images, although uptake in these ganglia was lower than in most tumor lesion: The average ${ }^{68} \mathrm{Ga}-\mathrm{HBED}-\mathrm{CC}-\mathrm{PSM} \mathrm{A}$ maximum lesion to mean background uptake ratio of lymph node metastases was 23.3 (range 5.3-115.8), whereas the average ratio for ganglia was 8.0 (range 2.8-30.6).

\section{PET/CT imaging with F-18-labeled PSMA lig- ands}

Several groups have focused on the development of ${ }^{18} \mathrm{~F}$-labeled PSMA ligands for imaging of PCa. An advantage of the use of ${ }^{18} \mathrm{~F}$ as a radionuclide is the fact that it allows centralized production and commercial distribution in greater areas and eliminates the need for on-site radiolabeling. In addition, multiple doses of ${ }^{18} \mathrm{~F}$ can be produced in one synthesis, while no more than 2 doses of ${ }^{68} \mathrm{Ga}$ can be synthezied at once. Moreover, imaging with ${ }^{18} \mathrm{~F}$ may result in higher image resolution and thus improved detection of tumor lesions.

One of the first ${ }^{18}$ F-labeled PSMA ligands clinically tested was developed by the group of Martin Pomper, who was one of the pioneers in the development of ${ }^{18} \mathrm{~F}$-labeled PSMA agents [45]. In this study, five patients with $\mathrm{PCa}$ and radiologic evidence for metastatic disease (median PSA $10.5 \mathrm{ng} / \mathrm{mL}$, range 9.4 - $46.5 \mathrm{ng} / \mathrm{mL}$ ) were investigated using N-[N[(S)-1,3-dicarboxypropyl] carbamoyl]-4-[18F]fluorobenzyl-L-cysteine ([18F]-DCFBC), a pentanedioic acid based compound. [ $\left.{ }^{18} \mathrm{~F}\right]-\mathrm{DCFBC}$ is structurally closely related to MIP-1072/1095, but labeled with ${ }^{18} \mathrm{~F}$ instead of ${ }^{99 \mathrm{mT}}$. Patients were investigated with both conventional imaging modalities (CIM) such as bone scintigraphy, CT, ultrasound, or MRI, and with PET/CT using [ $\left.{ }^{18} \mathrm{~F}\right]-\mathrm{DCFBC}$. Patients received 370 $\mathrm{MBq}$ of $\left[{ }^{18} \mathrm{~F}\right]-\mathrm{DCFBC}$, causing an estimated effective dose of $0.0199 \mathrm{mSv} / \mathrm{MBq}$. The organs which absorbed the highest dose were the urinary bladder wall $(0.0324$ $\mathrm{mGy} / \mathrm{MBq})$, stomach $(0.0302 \mathrm{mGy} / \mathrm{MBq})$, heart wall (0.0292 mGy/MBq) and kidneys (0.0284 mGy/MBq). Serial PET scans were performed until $2 \mathrm{~h}$ p.i. A total 
of 42 lesions were visualized with either CIM or PET/CT. Twenty-one of the 32 lesions seen with PET/CT were concordant with the conventional imaging methods. Nearly all PET-positive lesions that were not visualized with CIM were located in the skeleton, suggesting superiority of PET/CT in the detection of early bone metastases. Most of the CIM-positive but PET-negative lesions were clinically interpreted as remodeling changes or benign fractures. Based on these observations, the authors concluded that $\left[{ }^{18} \mathrm{~F}\right]-\mathrm{DCFBC}-\mathrm{PET} / \mathrm{CT}$ is feasible for detection of metastatic PCa lesions [45]. In a subsequent study, Rowe et al. evaluated the role of $\left[{ }^{18} \mathrm{~F}\right]-\mathrm{DCFBC}-\mathrm{PET} / \mathrm{CT}$ for detection and characterization of primary PCa [62]. In this study, MR imaging demonstrated greater sensitivity for the detection of PCa whereas ${ }^{18} \mathrm{~F}-\mathrm{DCFBC}-\mathrm{PET}$ can potentially allow for more specific localization of the highest grade and most clinically significant tumor lesions than MR imaging. ${ }^{18} \mathrm{~F}-\mathrm{DCFBC}-\mathrm{PET}$ was, however, limited for detection of smaller-sized $(<1.1 \mathrm{~mL})$ and lower-grade (Gleason 7 or 6) tumors. The value of $\left.{ }^{18} \mathrm{~F}\right]-\mathrm{DCFBC}-\mathrm{PET} / \mathrm{CT}$ may lie in the fact that relatively low ${ }^{18} \mathrm{~F}-\mathrm{DCFBC}$-PET uptake was observed in benign prostatic hypertrophy lesions, compared with cancer in the prostate, which may allow for more specific detection of primary $\mathrm{PCa}$ by ${ }^{18} \mathrm{~F}-\mathrm{DCFBC}-\mathrm{PET} / \mathrm{CT}$ [62].

Major disadvantage of $\left[{ }^{18} \mathrm{~F}\right]-\mathrm{DCFBC}$ is the considerable blood pool activity. This is most likely caused by binding of the tracer to plasma proteins, which results in slow clearance, low tumor-to-blood ratios, and potentially interferes with the detection of lower avidity or smaller tumor lesions [62]. To address this potential limitation, the group of Martin Pomper developed a second-generation ${ }^{18} \mathrm{~F}$-labeled PSMA ligand, 2-(3-(1-carboxy-5-[(6-[18 F]fluoropyridine-3-carbonyl)-amino]-pentyl)-ureido)-pentanedioic acid ([18F]-DCFPyL) [63, 64]. It was shown that the affinity of $\left[{ }^{18} \mathrm{~F}\right]$-DCFPyL for PSMA $(\mathrm{Ki}=1.1 \pm 0.1$ $\mathrm{nM})$ was more than five times higher than that of [18F]-DCFBC [64]. Preclinical imaging using $\left[{ }^{18} \mathrm{~F}\right]-\mathrm{DCFPyL}$ demonstrated PSMA-expressing to PSMA-negative tumor ratios exceeding 300:1 at $2 \mathrm{~h}$ post-injection with minimal non-target tissue uptake [64]. Tumor uptake was 8-fold higher using [ $\left.{ }^{18} \mathrm{~F}\right]$-DCFPyL compared to [ $\left.{ }^{18} \mathrm{~F}\right]$-DCFBC.

In a first-in-man evaluation in 9 patients with $\mathrm{PCa}$, it was shown that $\left[{ }^{18} \mathrm{~F}\right]-\mathrm{DCFPyL}$ is safe to administer and that the biodistribution pattern parallels the known tissue distribution of PSMA. Compared to [18F]-DCFBC, the tumor-to-blood ratios seen with $\left[{ }^{18} \mathrm{~F}\right]-\mathrm{DCFPyL}$ were notably higher. In addition, rapid plasma clearance and low accumulation in the liver and muscle as compared to tumors lead to high tu- mor-to-background ratios, resulting in a $\mathrm{SUV}_{\max }$ greater than 100 in some lesions, which the authors attribute to internalization of the compound. However, so far, no direct comparison between the internalization rates of $\left[{ }^{18} \mathrm{~F}\right]-\mathrm{DCFPyL}$ and $\left[{ }^{18} \mathrm{~F}\right]$-DCFBC has been described. In addition to tumor uptake, the tumor-to-blood ratios with $\left[{ }^{18} \mathrm{~F}\right]-\mathrm{DCFPyL}$ were notably higher than those of $\left.{ }^{18} \mathrm{~F}\right]-\mathrm{DCFBC}[63]$. These findings indicate superiority of $\left[{ }^{18} \mathrm{~F}\right]$-DCFPyL- to [18 $\mathrm{F}]$-DCFBC-PET/CT in the detection of PCa lesions. The limitation of high blood pool activity of $\left.{ }^{18} \mathrm{~F}\right]-\mathrm{DCFBC}$ has been overcome by the use of [18F]-DCFPyL.

Taken together, among the clinically tested PSMA inhibitors for PET imaging, ${ }^{68} \mathrm{Ga}-\mathrm{HBED}-\mathrm{CC}-\mathrm{PSMA}$ and $\left[{ }^{18} \mathrm{~F}\right]-\mathrm{DCFPyL}$ seem to be the most suitable tracers so far, as they are safe and provide high tumor uptake as well as high tumor-to-background ratios allowing high lesion detection rates. A direct comparison between both agents was recently described by Dietlein et al. [65]. In this study, 14 patients underwent both ${ }^{68} \mathrm{Ga}-H B E D-C C-P S M A-P E T / C T$ at $1 \mathrm{~h}$ p.i. and [18F]-DCFPyL-PET/CT at $2 \mathrm{~h}$ p.i.. It was shown that all lesions identified with ${ }^{68} \mathrm{Ga}-\mathrm{HBED}-\mathrm{CC}-\mathrm{PSMA}-$ PET/CT were detected with [18F]-DCFPyL-PET/CT. Most importantly, additional suspicious PCa lesions were detected in $3 / 14$ patients with $\left[{ }^{18} \mathrm{~F}\right]-\mathrm{DCFPyL}$, suggesting a higher sensitivity of $\left.{ }^{18} \mathrm{~F}\right]-\mathrm{DCFPyL}-$ PET/CT. In addition, significantly higher $\mathrm{SUV}_{\max }$ values and higher tumor-to-background ratios were obtained with $\left[{ }^{18} \mathrm{~F}\right]-\mathrm{DCFPyL}$ than with ${ }^{68} \mathrm{Ga}-\mathrm{HBED}-\mathrm{CC}-\mathrm{PSMA}$. The authors hypothesize that the higher detection rate of $\left[{ }^{18} \mathrm{~F}\right]$-DCFPyL-PET/CT was at least partly due to the fact that $\left.{ }^{18} \mathrm{~F}\right]-\mathrm{DCFPyL}$ allowed later acquisition times, potentially leading to images with better signal-to-noise ratios. In addition, the faster clearance of $\left[{ }^{18} \mathrm{~F}\right]-\mathrm{DCFPyL}$ from the background might have contributed to the improved detection rate. Overall, this study suggests that $\left[{ }^{18} \mathrm{~F}\right]-\mathrm{DCFPyL}$ may be a superior alternative to ${ }^{68} \mathrm{Ga}-H B E D-C C-P S M A$ for imaging of recurrent PCa. However, further studies in larger patient cohorts are required to confirm these findings.

While, so far, a considerable amount of attention was focused on the role of serum PSA levels on PSMA imaging, the role of androgen-deprivation therapy on PSMA imaging has not been evaluated clinically and remains unclear. Therefore, in future, clinical studies are needed that carefully characterize the influence of androgen-deprivation therapy on PSMA expression and the visualization of PSMA-expressing tumor lesions with PSMA-PET/CT. 


\section{PSMA Ligand-Based Radionuclide Therapy of Prostate Cancer}

Besides diagnostic imaging, radiolabeled PSMA ligands also have potential for radionuclide therapy of PCa. Zechmann et al. treated 28 patients with metastatic castrate-resistant $\mathrm{PCa}$ with a single therapeutic dose of 131 I-MIP-1095 (mean activity: $4.8 \mathrm{GBq}$, range 2 - 7.2 GBq) [46]. In this study, the estimated radiation doses were compared with those reported for the ${ }^{177} \mathrm{Lu}$-labeled anti-PSMA antibody J591. This comparison revealed that the effective doses to the tumor obtained with ${ }^{131}$ I-MIP-1095 were markedly higher than those obtained with ${ }^{177} \mathrm{Lu}-\mathrm{J} 591$, while red marrow and kidney doses were similar when using ${ }^{131}$ I-MIP-1095 [66], which showed the potential of these radiolabeled PSMA ligands for radionuclide therapy. PSMA uptake in healthy human tissue, such as the kidneys, salivary glands and the lower intestines renders these tissues prone to toxic side effects $[22,52,67]$. No impairment of kidney function was observed in the study by Zechmann et al., as the glomerular filtration rate and creatinine levels remained normal within one year after treatment. The main observed side effects were a result of high salivary gland uptake; seven patients reported a dry mouth and in one patient, mucositis was observed. These symptoms disappeared 3-4 weeks after the treatment. Hematological toxicity of these doses of ${ }^{131}$ I-MIP-1095 was mild. In 14 patients white blood cell counts fell below the normal range after therapy (10 patients with grade 1, 3 with grade 2 and one with grade 3 toxicity). However, five of these 14 patients had levels below normal prior to therapy (4 grade 1, one with grade 2). Erythrocytes counts fell below the normal range 21 patients with 17 patients having lower values prior to therapy. Eleven patients had a reduction in platelet counts below normal after therapy, among which one patient had a value below normal prior to therapy.

Administration of therapeutic doses of ${ }^{131}$ I-MIP-1095 demonstrated high levels of tumor uptake and prolonged retention up to 17 days after administration. Therapeutic efficacy was demonstrated by symptom relief and by a decrease in serum PSA levels. After a single dose of up to $7.2 \mathrm{GBq}$ ${ }^{131}$ I-MIP-1095, in $61 \%$ of the patients, a decline in serum PSA levels of $\geq 50 \%$ was observed; seven patients (25\%) had more than a $75 \%$ decline in PSA level, and $10(35.7 \%)$ had a drop between 50 and $75 \%$. Only 2 patients $(7.1 \%)$ had a decline between $25 \%$ and $50 \%$, and $2(7.1 \%)$ between 0 and $25 \%$. In only four patients, an increase of PSA was observed. A decrease in PSA was associated with a decrease in number and/or intensity of the lesions visualized on the post therapeutic PET/CT scan with ${ }^{68} \mathrm{Ga}-\mathrm{PMSA}-\mathrm{HBED}-$ CC. The median time to PSA progression was 126 days. Longer lasting responses may be obtained when consecutive doses of ${ }^{131}$ I-MIP-1095 will be administered. Zechmann et al. showed that a therapeutic dose of ${ }^{131}$ I-MIP-1095 could be safely administered to patients with metastatic PCa, while keeping the radiation dose to the healthy tissues at an acceptable level.

The tissue penetration range of $\beta$-particles of ${ }^{177} \mathrm{Lu}$ for radionuclide therapy is comparable to that of ${ }^{131} \mathrm{I}$. However, one advantage of the use of ${ }^{177} \mathrm{Lu}$ might be the fact that ${ }^{177} \mathrm{Lu}$ is easier to distribute to centers where therapy with this radionuclide is provided. In addition, ${ }^{177} \mathrm{Lu}$ presents a lower proportion of $\gamma$-radiation, which could result in a reduced stay in the hospital and lower hematological toxicity compared with 131I [68]. Benesová et al. developed the novel theranostic PSMA agent ${ }^{177} \mathrm{Lu}-\mathrm{DKFZ}-617$, which is a DOTA-conjugated Glu-urea-Lys analogue for both ${ }^{177} \mathrm{Lu}-$ and ${ }^{68} \mathrm{Ga}-$ labeling [69]. Preclinically, DKFZ-617 showed high tumor-to-background contrasts as early as $1 \mathrm{~h}$ after injection. Specific uptake was observed in PSMA-expressing tumors and in the kidneys. With regard to therapeutic use, the compound exhibited a rapid clearance from the kidneys from $113.3 \pm 24.4$ at $1 \mathrm{~h}$ to $2.1 \pm 1.4 \%$ ID/g at $24 \mathrm{~h}$. High tumor-to-muscle ratios at $24 \mathrm{~h}$ p.i. were reported. Overall, the fast kidney clearance encouraged transfer of this compound into the clinics.

Kratochwil et al. evaluated the therapeutic potential of ${ }^{177} \mathrm{Lu}$-DKFZ-617 in one patient with metastatic PCa [70]. In DKFZ-617, the chelator is conjugated via a linker containing two aromatic rings which is considered to improve tumor accumulation and reduce kidney uptake. In this report, one patient was treated with a cumulative activity of $7.4 \mathrm{GBq}$ of ${ }^{177} \mathrm{Lu}-\mathrm{DKFZ}-617$. In pre-therapeutic PSMA PET/CT, a tumor phenotype with high PSMA ligand uptake was observed. After therapy, restaging with PSMA PET/CT revealed a striking radiological response and a decrease in PSA level from 38.0 to $4.6 \mathrm{ng} / \mathrm{ml}$ [70]. A prospective multicenter study to further evaluate the clinical potential of ${ }^{177} \mathrm{Lu}-\mathrm{DKFZ}-617$ is currently planned.

Baum et al. evaluated the role of ${ }^{177} \mathrm{Lu}-\mathrm{DKFZ}-617$ radionuclide therapy in a greater group of patients with PCa $(n=53)$ [71]. In this study, 34 out of 53 patients received multiple therapy cycles (range: $2-5$ ). The mean injected activity of ${ }^{177} \mathrm{Lu}-\mathrm{PSMA}$ per cycle was $5.7 \pm 0.8 \mathrm{GBq}$ (median, 5.8 GBq). The authors report a molecular treatment response (partial remission) in 11 patients and a morphological response in 6 patients. Stable disease was noted in 5 and 13 patients, according to molecular and morphological response criteria, respectively, whereas disease progressed in 8 
patients. In this study, all symptomatic patients reported significant improvement in pain and quality of life after therapy. The treatment was very well tolerated by all patients; no acute or long-term side effects were reported and no significant alterations in any of the laboratory parameters were observed. In particular, no hematological toxicity and change in renal function was observed.

However, as PSMA is specifically expressed in the renal tubules of the kidneys, there is a risk for renal toxicity which might be dose-limiting. In mice, Kratochwil et al. evaluated the role of the blocking agent 2-(phosphonomethyl)pentanedioic acid (PMPA), a known inhibitor of folate hydrolase activity of PSMA, in an attempt to block PSMA expressed in the kidneys [72]. BALB/c nude mice with subcutaneous $\mathrm{PSMA}^{+} \mathrm{LNCaP}$ xenografts received different doses of PMPA at $16 \mathrm{~h}$ after injections of 125I-MIP-1095, so the tracer would have sufficient time for tumor uptake and internalization as well as for tracer clearance from the bloodstream and kidney calices. It was demonstrated, that kidney uptake could be lowered without significantly diminishing tumor uptake. However, clinical studies that evaluate the potential of PMPA in patients have not yet been performed.

Overall, promising preliminary clinical data encourage further studies to evaluate the potential of endoradiotherapy of PCa using PSMA ligands. The added value of this therapeutic regimen needs to be compared to conventional PCa therapies.

\section{Theranostics Using PSMA Ligands}

With several PSMA ligands currently being tested clinically for diagnostic and therapeutic purposes, agents which allow both diagnosis and therapy of PCa are getting more and more desirable. One of these agents that allows labeling with both ${ }^{68} \mathrm{Ga}$ and ${ }^{177} \mathrm{Lu}$ is DKFZ-617 (mentioned above). This compound can thus be used for diagnostic and therapeutic purposes [70,71]. However, it was shown previously that DOTA-coupled PSMA ligands show significantly lower tumor uptake than HBED-CC-chelated agents [55]. In a first attempt to improve the pharmacokinetics of the DOTA-coupled PSMA ligands, the hydrophilicity of the ligand was increased by substitution of DOTA by 1,4,7,10-tetraazacyclodocecane,1-(glutaric acid)-4,7,10-triacetic acid (DOTAGA), resulting in DOTAGA-FFK(Sub-KuE) which can be labeled with both ${ }^{68} \mathrm{Ga}$ and ${ }^{177} \mathrm{Lu}$ and thus potentially be used for diagnostic and therapeutic purposes [73]. It was shown that DOTAGA-conjugated ligand complexes showed a significantly increased affinity towards PSMA on PSMA-expressing LNCaP cells compared to the DOTA-conjugated PSMA ligands [73].
In an initial study in patients with metastatic castration-resistant $\mathrm{PCa},{ }^{177} \mathrm{Lu}-\mathrm{DOTAGA-FFK}(\mathrm{Sub}-$ $\mathrm{KuE}$ ) caused a significant reduction in metastatic tumor load in some patients. To further improve the PSMA-affinity by increasing the lipophilic interaction of the tracer with the PSMA enzyme, a peptidic linker unit was introduced by Weineisen and colleagues in a subsequent study providing DOTAGA-(I-y)fk(Sub$\mathrm{KuE}$ ), termed PSMA I\&T (for Imaging and Therapy) [74]. Compared with ${ }^{177} \mathrm{Lu}-\mathrm{DOTAGA}-\mathrm{FFK}(\mathrm{Sub}-\mathrm{KuE})$, ${ }^{177} \mathrm{Lu}-\mathrm{PSMA}$ I\&T was shown to have higher internalization capacity, which might improve tumor uptake [74]. In this study, one patient underwent ${ }^{8} \mathrm{Ga}$-PSMA I\&T PET/CT imaging which revealed high uptake in a primary prostate lesion $\left(\mathrm{SUV}_{\max } 65.1\right)$ and a perirectal lymph node $\left(S_{U V} V_{\max } 15.0\right)$. Another patient was treated with $200 \mu \mathrm{g}(8.0 \mathrm{GBq})$ of ${ }^{177} \mathrm{Lu}-\mathrm{PSMA}$ I\&T, which resulted in partial remission of many of the intense PSMA-positive metastatic lesions depicted by pre-therapeutic ${ }^{68} \mathrm{Ga}-\mathrm{PSMA}-\mathrm{HBED}-\mathrm{CC} \quad \mathrm{PET} / \mathrm{CT}$ which was accompanied by a drop in $\mathrm{SUV}_{\max }$ from 26.3 to 3.0 in a paraaortic lymph node and a significant drop in PSA serum level from 54.2 to $0.7 \mathrm{ng} / \mathrm{ml}$ [74]. In addition, symptomatic pain relief was reported. Taken together, these results suggest high potential of ${ }^{177} \mathrm{Lu}$-PSMA I\&T radionuclide therapy in the destruction of PCa lesions.

Subsequently, Herrmann et al. have evaluated the biodistribution and radiation dosimetry of ${ }^{68} \mathrm{Ga}$-PSMA I\&T in 5 patients [75]. It was shown that ${ }^{68} \mathrm{Ga}$-PSMA I\&T exhibits promising dosimetry which compares favorably with other PCa specific probes such as ${ }^{123}$ I-MIP-1072 or -1095 [75]. ${ }^{68} \mathrm{Ga}$-PSMA I\&T was tolerated by all patients without acute or subacute adverse events and without significant changes in blood count, kidney or hepatic function. High lesion-to-background uptake ratios were observed as early as 30min after administration, however, the best contrast was achieved at $1 \mathrm{~h}$ p.i..

Taken together, these promising preliminary results suggest that PSMA I\&T can be used for both diagnostic imaging as well as for radionuclide therapy. However, even though the potential theranostic uses of ${ }^{68} \mathrm{Ga}$-PSMA I\&T are appealing, as far as we know, no direct comparison between ${ }^{68} \mathrm{Ga}-\mathrm{PSMA}$ I\&T-PET/CT and ${ }^{68}$ Ga-HBED-CC-PSMA-PET/CT concerning diagnostic imaging of $\mathrm{PCa}$ has been performed, yet. Therefore, before a theranostic compound could replace the so far more frequently tested ${ }^{68} \mathrm{Ga}-\mathrm{HBED}-\mathrm{CC}-\mathrm{PSMA}-\mathrm{PET} / \mathrm{CT}$, diagnostic accuracy of both agents needs to be directly compared to each other.

In addition, other tracers which so far have mainly been used for therapeutic strategies might be used for diagnostic applications, too, such as the 
DOTA-conjugated DKFZ-617 PSMA ligand.

\section{Surgical Guidance with PSMA Ligands}

Next to diagnostic applications and endoradiotherapy, PSMA ligands can potentially be used for other therapeutic strategies such as image-guided surgery of PCa lesions. At present, radical prostatectomy represents the gold standard in surgical treatment of PCa. However, frequently, small amounts of tumor tissue as well as micrometastases cannot be visualized during surgery and are not resected, potentially causing recurrence of the disease [76]. To avoid this, imaging techniques are needed that allow real-time intra-operative visualization and image-guided resection of small amounts of residual tumor tissue.

Potentially, PCa lesions can be detected intra-operatively using radio-guided surgery. While imaging of even small and metastatic PCa lesions and lymph nodes is possible with PET/CT using ${ }^{68} \mathrm{Ga} /{ }^{18} \mathrm{~F}$-labeled PSMA ligands, intraoperative detection of such lesions may not be easy owing to their inconspicuous morphology and atypical localization. To improve intra-operative lesion detection and allow radio-guided surgery, Maurer et al. developed radio-guided surgery for PCa using ${ }^{111}$ In-labeled PSMA ligands [77]. Because of its favorable half-life of $2.8 \mathrm{~d}$, initially PSMA-HBED-CC was labeled with ${ }^{111} \mathrm{In}$. However, due to instability of this complex, ${ }^{111}$ In-PSMA I\&T was used for radio-guided surgery instead. Five patients underwent ${ }^{68} \mathrm{Ga}$-PSMA-HBED-CC-PET/CT followed by surgery with intra-operative detection of tumor lesions using a gamma probe at $24 \mathrm{~h}$ after injection of $146 \mathrm{MBq}$ (110-169MBq) of ${ }^{111}$ In-PSMA I\&T. All PET-positive lesions were detected by PSMA-radio-guided surgery. Histologic analyses confirmed that all resected tissue specimens exhibiting positive measurements in vivo and ex vivo were PSMA positive. Moreover, additional tumor lesions of $2-4 \mathrm{~mm}$ size close to known tumor deposits were identified in 2 of 5 patients. Overall, this study shows that radio-guided surgery can lead to improvements in the resection of PCa.

Another approach to detect tumor lesions intra-operatively for image-guided resection is by using in vivo fluorescence imaging. Neuman et al. evaluated the role of the low-molecular weight urea-based fluorescent agent YC-27, 2-(3-\{5-[7-(5-amino-1-carboxypentylcarbamoyl)-heptanoylamino]-1-carboxy-

pentyl\}-ureido) pentanedioic acid conjugated to the near-infrared fluorescent dye IRDye800CW [78] for real-time near-infrared fluorescence imaging of surgical margins and image-guided resection of remaining PCa lesions in a mouse model of PCa [76]. In this study, nu/nu mice with subcutaneous
PSMA-expressing tumors received intravenous injections of $19.1 \mu \mathrm{g} / \mathrm{kg}$ of YC-27 and underwent image-guided surgery with a fluorescence imaging system. Within 30 days after surgery, none of the animals resected with image-guidance developed a recurrence, while $40 \%$ of the animals with tumors resected by conventional surgery had recurrent disease within that period of time. These data indicate that a near-infrared fluorophore targeted to PSMA allows improvements in surgical treatment of PCa by reduction of positive surgical margins. One potential advantage above radio-guided surgery might be the fact that the fluorescence system allows real-time visualization of tumor tissue instead of localization based on acoustic signals as it is the case for radio-guided strategies. However, the use of fluorescence is restricted by the relatively low tissue penetration depth of $1-2 \mathrm{~cm}$ of emitted near-infrared light. To overcome the limitations of both radio-guidance and fluorescent approaches, a dual-labeling approach in which PSMA ligands are conjugated to both a fluorescent label as well as a radionuclide would be needed, which allows both visual and acoustic tumor detection.

\section{Conclusion and Future Perspectives}

Diagnosis, (re)staging, and therapy of PCa entail different challenges in the management of patients with PCa, which still pose major challenges to today`s medical care. PSMA ligands show great potential for initial staging, lymph node staging, and restaging of PCa. With PSMA ligands, limitations of choline-based imaging, such as the relatively low sensitivity, especially in patients with low PSA levels and Gleason scores, can be overcome. In addition, first clinical studies show the potential of PSMA ligands for therapeutic strategies such as targeted radiation delivery

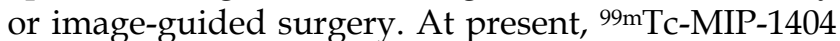
seems to be the most promising tracer for SPECT imaging of $\mathrm{PCa}$, while ${ }^{68} \mathrm{Ga}$-labeled HBED-CC-PSMA and ${ }^{18} \mathrm{~F}$-labeled DCFPyl represent the most promising tracers for PET imaging of patients with PCa. Further studies that directly compare both agents under identical conditions are needed, to identify which agent is superior. Unfortunately, so far, both ${ }^{68} \mathrm{Ga}-\mathrm{HBED}-\mathrm{CC}-$ PSMA and ${ }^{18} \mathrm{~F}-\mathrm{DCFPyl}$ are restricted to diagnostic purposes. An interesting variant that potentially combines both diagnosis and therapy of $\mathrm{PCa}$ are the compounds DKFZ-617 and PSMA I\&T as they can be labeled with ${ }^{68} \mathrm{Ga}$ for diagnostic purposes as well as with ${ }^{177} \mathrm{Lu}$ for therapeutic approaches. In future, more research on imaging and therapy of PCa with PSMA ligands in patient cohorts exhibiting low PSA levels in particular is needed to determine up to which PSA levels imaging with PSMA ligands can uphold its high sensitivity. Moreover, PSMA imaging studies 
need to be performed in PCa patients that have recently received or are under androgen deprivation therapy to investigate the role of PSMA imaging in this patient population. In addition, the potential of PSMA ligand-based imaging and therapy of soft-tissue and bone metastases should be evaluated.

Another interesting application of PCa would be intra-operative detection and radio/image-guided resection of tumor lesions within the prostate as well as of tumor-containing lymph nodes. For this purpose, dual-labeling strategies using fluorescent and radionuclide imaging are desirable, which allow pre-operative visualization of PCa lesions by radionuclide imaging techniques as well as intra-operative acoustic and visual localization of PSMA-expressing tumor lesions, permitting signal-guided resection of tumors.

\section{Competing Interests}

The authors have declared that no competing interest exists.

\section{References}

1. Jana S, Blaufox MD. Nuclear medicine studies of the prostate, testes, and bladder. Semin Nucl Med. 2006; 36: 51-72.

2. Gambhir SS, Czernin J, Schwimmer J, Silverman DH, Coleman RE, Phelps ME. A tabulated summary of the FDG PET literature. J Nucl Med. 2001; 42: 1S-93S.

3. Bouchelouche K, Tagawa ST, Goldsmith SJ, Turkbey B, Capala J, Choyke P. PET/CT Imaging and Radioimmunotherapy of Prostate Cancer. Semin Nucl Med. 2011; 41: 29-44.

4. Ackerstaff E, Glunde K, Bhujwalla ZM. Choline phospholipid metabolism: a target in cancer cells? J Cell Bioochem. 2003; 90: 525-33.

5. Glunde K, Ackerstaff E, Mori N, Jacobs MA, Bhujwalla ZM. Choline phospholipid metabolism in cancer: consequences for molecular pharmaceutical interventions. Mol Pharm. 2006; 3: 496-506.

6. Kitajima K, Murphy RC, Nathan MA. Choline PET/CT for imaging prostate cancer: an update. Ann Nucl Med. 2013 27: 581-91.

7. Umbehr MH, Muntener M, Hany T, Sulser T, Bachmann LM. The role of 11C-choline and 18F-fluorocholine positron emission tomography (PET) and PET/CT in prostate cancer: a systematic review and meta-analysis. Eur Urol. 2013; 64: 106-17.

8. Krause BJ, Souvatzoglou M, Treiber U. Imaging of prostate cancer with PET/CT and radioactively labeled choline derivates. Urol Oncol. 2013; 31: $427-35$

9. Bauman G, Belhocine T, Kovacs M, Ward A, Beheshti M, Rachinsky I. 18F-fluorocholine for prostate cancer imaging: a systematic review of the literature. Prostate cancer Prostatic Dis. 2012; 15: 45-55.

10. Castellucci P, Ceci F, Graziani T, Schiavina R, Brunocilla E, Mazzarotto R, et al. Early biochemical relapse after radical prostatectomy: which prostate cancer patients may benefit from a restaging 11C-Choline PET/CT scan before salvage radiation therapy? J Nucl Med. 2014; 55: 1424-9.

11. Lutje S, Boerman OC, van Rij CM, Sedelaar M, Helfrich W, Oyen WJ, et al. Prospects in radionuclide imaging of prostate cancer. Prostate. 2012; 72: 1262-72.

12. Israeli RS, Powell CT, Fair WR, Heston WD. Molecular cloning of a complementary DNA encoding a prostate-specific membrane antigen. Cancer Res. 1993; 53: 227-30.

13. Zhou J, Neale JH, Pomper MG, Kozikowski AP. NAAG peptidase inhibitors and their potential for diagnosis and therapy. Nat Rev Drug Discov. 2005; 4: 1015-26.

14. Silver DA, Pellicer I, Fair WR, Heston WD, Cordon-Cardo C. Prostate-specific membrane antigen expression in normal and malignant human tissues. Clin Cancer Res. 1997; 3: 81-5.

15. Conway RE, Petrovic N, Li Z, Heston W, Wu D, Shapiro LH. Prostate-specific membrane antigen regulates angiogenesis by modulating integrin signal transduction. Mol Cell Biol. 2006; 26: 5310-24.

16. Minner S, Wittmer C, Graefen M, Salomon G, Steuber T, Haese A, et al. High level PSMA expression is associated with early PSA recurrence in surgically treated prostate cancer. Prostate. 2011; 71: 281-8.

17. Rybalov M, Ananias HJ, Hoving HD, van der Poel HG, Rosati S, de Jong IJ. PSMA, EpCAM, VEGF and GRPR as imaging targets in locally recurrent prostate cancer after radiotherapy. Int J Mol Sci. 2014; 15: 6046-61.
18. Ananias HJ, van den Heuvel MC, Helfrich W, de Jong IJ. Expression of the gastrin-releasing peptide receptor, the prostate stem cell antigen and the prostate-specific membrane antigen in lymph node and bone metastases of prostate cancer. Prostate. 2009; 69: 1101-8.

19. Kawakami M, Nakayama J. Enhanced expression of prostate-specific membrane antigen gene in prostate cancer as revealed by in situ hybridization. Cancer Res. 1997; 57: 2321-4.

20. Bostwick DG, Pacelli A, Blute M, Roche P, Murphy GP. Prostate specific membrane antigen expression in prostatic intraepithelial neoplasia and adenocarcinoma: a study of 184 cases. Cancer. 1998; 82: 2256-61.

21. Graham K, Lesche R, Gromov AV, Bohnke N, Schafer M, Hassfeld J, et al. Radiofluorinated derivatives of 2-(phosphonomethyl)pentanedioic acid as inhibitors of prostate specific membrane antigen (PSMA) for the imaging of prostate cancer. J Med Chem. 2012; 55: 9510-20.

22. Troyer JK, Beckett ML, Wright GL, Jr. Detection and characterization of the prostate-specific membrane antigen (PSMA) in tissue extracts and body fluids. Int J Cancer. 1995; 62: 552-8.

23. Wright GL, Jr., Grob BM, Haley C, Grossman K, Newhall K, Petrylak D, et al. Upregulation of prostate-specific membrane antigen after androgen-deprivation therapy. Urology. 1996; 48: 326-34.

24. Ross JS, Sheehan CE, Fisher HA, Kaufman RP, Jr., Kaur P, Gray K, et al. Correlation of primary tumor prostate-specific membrane antigen expression with disease recurrence in prostate cancer. Clin Cancer Res. 2003; 9: 6357-62.

25. Horoszewicz JS, Kawinski E, Murphy GP. Monoclonal antibodies to a new antigenic marker in epithelial prostatic cells and serum of prostatic cancer patients. Anticancer Res. 1987; 7: 927-35.

26. Franc BL, Cho SY, Rosenthal SA, Cui Y, Tsui B, Vandewalker KM, et al. Detection and localization of carcinoma within the prostate using high resolution transrectal gamma imaging (TRGI) of monoclonal antibody directed at prostate specific membrane antigen (PSMA)--proof of concept and initial imaging results. Eur J Radiol. 2013; 82: 1877-84

27. Ponsky LE, Cherullo EE, Starkey R, Nelson D, Neumann D, Zippe CD. Evaluation of preoperative ProstaScint scans in the prediction of nodal disease. Prostate cancer Prostatic Dis. 2002; 5: 132-5.

28. Liu H, Rajasekaran AK, Moy P, Xia Y, Kim S, Navarro V, et al. Constitutive and antibody-induced internalization of prostate-specific membrane antigen. Cancer Res. 1998; 58: 4055-60.

29. Bander NH, Trabulsi EJ, Kostakoglu L, Yao D, Vallabhajosula S, Smith-Jones P, et al. Targeting metastatic prostate cancer with radiolabeled monoclonal antibody J591 to the extracellular domain of prostate specific membrane antigen. Urol. 2003; 170: 1717-21.

30. Tagawa ST, Milowsky MI, Morris M, Vallabhajosula S, Christos P, Akhtar NH, et al. Phase II study of Lutetium-177-labeled anti-prostate-specific membrane antigen monoclonal antibody J591 for metastatic castration-resistant prostate cancer. Clinical Cancer Res. 2013; 19: 5182-91.

31. Tsukamoto T, Wozniak KM, Slusher BS. Progress in the discovery and development of glutamate carboxypeptidase II inhibitors. Drug Discov Today. 2007; 12: 767-76.

32. Foss CA, Mease RC, Fan H, Wang Y, Ravert HT, Dannals RF, et al. Radiolabeled small-molecule ligands for prostate-specific membrane antigen: in vivo imaging in experimental models of prostate cancer. Clin Cancer Res. 2005; $11: 4022-8$

33. Mease RC, Dusich CL, Foss CA, Ravert HT, Dannals RF, Seidel J, et al. $\mathrm{N}-[\mathrm{N}-[(\mathrm{S})-1,3-$ Dicarboxypropyl]carbamoyl]-4-[18F]fluorobenzyl-L-cysteine, [18F]DCFBC: a new imaging probe for prostate cancer. Clin Cancer Res. 2008; 14: 3036-43.

34. Maresca KP, Hillier SM, Femia FJ, Keith D, Barone C, Joyal JL, et al. A series of halogenated heterodimeric inhibitors of prostate specific membrane antigen (PSMA) as radiolabeled probes for targeting prostate cancer. J Med Chem. 2009; 52: 347-57.

35. Banerjee SR, Foss CA, Castanares M, Mease RC, Byun Y, Fox JJ, et al. Synthesis and evaluation of technetium-99m- and rhenium-labeled inhibitors of the prostate-specific membrane antigen (PSMA). J Med Chem. 2008; 51: 4504-17.

36. Hillier SM, Maresca KP, Lu G, Merkin RD, Marquis JC, Zimmerman CN, et al. $99 \mathrm{mTc}$-labeled small-molecule inhibitors of prostate-specific membrane antigen for molecular imaging of prostate cancer. J Nucl Med. 2013; 54: 1369-76.

37. Banerjee SR, Pullambhatla M, Byun Y, Nimmagadda S, Green G, Fox JJ, et al. 68Ga-labeled inhibitors of prostate-specific membrane antigen (PSMA) for imaging prostate cancer. J Med Chem. 2010; 53. 5333-41.

38. Schafer M, Bauder-Wust U, Leotta K, Zoller F, Mier W, Haberkorn U, et al. A dimerized urea-based inhibitor of the prostate-specific membrane antigen for 68Ga-PET imaging of prostate cancer. EJNMMI Res. 2012; 2: 23.

39. Chen Y, Pullambhatla M, Banerjee SR, Byun Y, Stathis M, Rojas C, et al. Synthesis and biological evaluation of low molecular weight fluorescent imaging agents for the prostate-specific membrane antigen. Bioconjug Chem. 2012; 23 : 2377-85.

40. Mesters JR, Barinka C, Li W, Tsukamoto T, Majer P, Slusher BS, et al. Structure of glutamate carboxypeptidase II, a drug target in neuronal damage and prostate cancer. EMBO J. 2006; 25: 1375-84

41. Huang SS, Wang X, Zhang Y, Doke A, DiFilippo FP, Heston WD. Improving the biodistribution of PSMA-targeting tracers with a highly negatively charged linker. Prostate. 2014; 74: 702-13.

42. Benesova M, Schafer M, Bauder-Wust U, Afshar-Oromieh A, Kratochwil C, Mier W, et al. Preclinical evaluation of a tailor-made DOTA-conjugated PSMA 
inhibitor with optimized linker moiety for imaging and endoradiotherapy of prostate cancer. J Nucl Med. 2015.

43. Barrett JA, Coleman RE, Goldsmith SJ, Vallabhajosula S, Petry NA, Cho S, et al. First-in-man evaluation of 2 high-affinity PSMA-avid small molecules for imaging prostate cancer. J Nucl Med. 2013; 54: 380-7.

44. Vallabhajosula S, Nikolopoulou A, Babich JW, Osborne JR, Tagawa ST, Lipai I, et al. 99mTc-labeled small-molecule inhibitors of prostate-specific membrane antigen: pharmacokinetics and biodistribution studies in healthy subjects and patients with metastatic prostate cancer. J Nucl Med. 2014; 55: 1791-8.

45. Cho SY, Gage KL, Mease RC, Senthamizhchelvan S, Holt DP, Jeffrey-Kwanisai A, et al. Biodistribution, tumor detection, and radiation dosimetry of 18F-DCFBC, a low-molecular-weight inhibitor of prostate-specific membrane antigen, in patients with metastatic prostate cancer. J Nucl Med. 2012; 53: 1883-91.

46. Zechmann CM, Afshar-Oromieh A, Armor T, Stubbs JB, Mier W, Hadaschik B, et al. Radiation dosimetry and first therapy results with a (124)I/ (131)I-labeled small molecule (MIP-1095) targeting PSMA for prostate cancer therapy. Eur J Nucl Med Mol Imaging. 2014; 41: 1280-92.

47. Afshar-Oromieh A, Zechmann CM, Malcher A, Eder M, Eisenhut M, Linhart HG, et al. Comparison of PET imaging with a (68)Ga-labelled PSMA ligand and (18)F-choline-based PET/CT for the diagnosis of recurrent prostate cancer. Eur J Nucl Med Mol Imaging. 2014; 41: 11-20.

48. Afshar-Oromieh A, Malcher A, Eder M, Eisenhut M, Linhart HG, Hadaschik $\mathrm{BA}$, et al. PET imaging with a [68Ga]gallium-labelled PSMA ligand for the diagnosis of prostate cancer: biodistribution in humans and first evaluation of tumour lesions. Eur J Nucl Med Mol Imaging. 2013; 40: 486-95.

49. Afshar-Oromieh A, Haberkorn U, Schlemmer HP, Fenchel M, Eder M, Eisenhut M, et al. Comparison of PET/CT and PET/MRI hybrid systems using a 68Ga-labelled PSMA ligand for the diagnosis of recurrent prostate cancer: initial experience. Eur J Nucl Med Mol Imaging. 2014; 41: 887-97.

50. Hillier SM, Maresca KP, Femia FJ, Marquis JC, Foss CA, Nouyen N, et al. Preclinical evaluation of novel glutamate-urea-lysine analogues that target prostate-specific membrane antigen as molecular imaging pharmaceuticals for prostate cancer. Cancer Res. 2009; 69: 6932-40.

51. Maresca KP, Marquis JC, Hillier SM, Lu G, Femia FJ, Zimmerman CN, et al. Novel polar single amino acid chelates for technetium-99m tricarbonyl-based radiopharmaceuticals with enhanced renal clearance: application to octreotide. Bioconjug Chem. 2010; 21:1032-42.

52. O'Keefe DS, Bacich DJ, Heston WD. Comparative analysis of prostate-specific membrane antigen (PSMA) versus a prostate-specific membrane antigen-like gene. Prostate. 2004; 58: 200-10.

53. Reubi JC, Maecke HR. Peptide-based probes for cancer imaging. J Nucl Med. 2008; 49: 1735-8

54. Roesch F, Riss PJ. The renaissance of the $(6)(8) \mathrm{Ge} /(6)(8) \mathrm{Ga}$ radionuclide generator initiates new developments in (6)(8)Ga radiopharmaceutical chemistry. Curr Top Med Chem. 2010; 10: 1633-68.

55. Eder M, Schafer M, Bauder-Wust U, Hull WE, Wangler C, Mier W, et al. 68Ga-complex lipophilicity and the targeting property of a urea-based PSMA inhibitor for PET imaging. Bioconjug Chem. 2012; 23: 688-97.

56. Morigi JJ, Stricker P, Van Leeuwen P, Tang R, Ho B, Nguyen Q, et al. Prospective Comparison of the detection rate of 18F-Fluoromethylcholine and 68Ga-PSMA-HBED PET/CT in men with prostate cancer with rising PSA post curative treatment, being considered for targeted therapy. J Nucl Med. 2015; 56: $1185-90$.

57. Afshar-Oromieh A, Avtzi E, Giesel FL, Holland-Letz T, Linhart HG, Eder M, et al. The diagnostic value of PET/CT imaging with the (68)Ga-labelled PSMA ligand HBED-CC in the diagnosis of recurrent prostate cancer. Eur J Nucl Med Mol Imaging. 2015; 42: 197-209.

58. Eiber M, Maurer T, Souvatzoglou M, Beer AJ, Ruffani A, Haller B, et al. Evaluation of Hybrid 68Ga-PSMA Ligand PET/CT in 248 Patients with Biochemical Recurrence After Radical Prostatectomy. J Nucl Med. 2015; 56: 668-74.

59. Brogsitter C, Zophel K, Kotzerke J. 18F-Choline, 11C-choline and 11C-acetate PET/CT: comparative analysis for imaging prostate cancer patients. Eur J Nucl Med Mol Imaging. 2013; 40 Suppl 1: S18-27.

60. Ceci F, Uprimny C, Nilica B, Geraldo L, Kendler D, Kroiss A, et al. (68)Ga-PSMA PET/CT for restaging recurrent prostate cancer: which factors are associated with PET/CT detection rate? Eur J Nucl Med Mol Imaging. 2015; 42: 1284-94.

61. Krohn T, Verburg FA, Pufe T, Neuhuber W, Vogg A, Heinzel A, et al. [(68)Ga]PSMA-HBED uptake mimicking lymph node metastasis in coeliac ganglia: an important pitfall in clinical practice. Eur J Nucl Med Mol Imaging. 2015; 42: 210-4.

62. Rowe SP, Gage KL, Faraj SF, Macura KJ, Cornish TC, Gonzalez-Roibon N, et al. 18F-DCFBC PET/CT for PSMA-Based Detection and Characterization of Primary Prostate Cancer. J Nucl Med. 2015; 56: 1003-10.

63. Szabo Z, Mena E, Rowe SP, Plyku D, Nidal R, Eisenberger MA, et al. Initial Evaluation of [(18)F]DCFPyL for Prostate-Specific Membrane Antigen (PSMA)-Targeted PET Imaging of Prostate Cancer. Mol Imaging Biol. 2015; 17: $565-74$

64. Chen Y, Pullambhatla M, Foss CA, Byun Y, Nimmagadda S, Senthamizhchelvan S, et $\quad$ et 2-(3-\{1-Carboxy-5)-pen tanedioic acid, [18F]DCFPyL, a PSMA-based PET imaging agent for prostate cancer. Clin Cancer Res. 2011; 17: 7645-53.
65. Dietlein M, Kobe C, Kuhnert G, Stockter S, Fischer T, Schomacker $\mathrm{K}$, et al. Comparison of [(18)F]DCFPyL and [ (68)Ga]Ga-PSMA-HBED-CC for PSMA-PET Imaging in Patients with Relapsed Prostate Cancer. Mol Imaging Biol. 2015; 17: 575-84.

66. Bander NH, Milowsky MI, Nanus DM, Kostakoglu L, Vallabhajosula S, Goldsmith SJ. Phase I trial of 177lutetium-labeled J591, a monoclonal antibody to prostate-specific membrane antigen, in patients with androgen-independent prostate cancer. J Clin Oncol. 2005; 23: 4591-601.

67. Kinoshita Y, Kuratsukuri K, Landas S, Imaida K, Rovito PM, Jr., Wang CY, et al. Expression of prostate-specific membrane antigen in normal and malignant human tissues. World J Surg. 2006; 30: 628-36.

68. Kassis AI. Therapeutic radionuclides: biophysical and radiobiologic principles. Semin Nucl Med. 2008; 38: 358-66.

69. Benesova M, Schafer M, Bauder-Wust U, Afshar-Oromieh A, Kratochwil C Mier W, et al. Preclinical Evaluation of a Tailor-Made DOTA-Conjugated PSMA Inhibitor with Optimized Linker Moiety for Imaging and Endoradiotherapy of Prostate Cancer. J Nucl Med. 2015; 56: 914-20.

70. Kratochwil C, Giesel FL, Eder M, Afshar-Oromieh A, Benesova M, Mier W, et al. [(177)Lu]Lutetium-labelled PSMA ligand-induced remission in a patient with metastatic prostate cancer. Eur J Nucl Med Mol Imaging. 2015; 42: 987-8.

71. Baum RP, Wahl RL. Third Theranostics World Congress on Gallium-68 and PRRT: Abstracts. J Nucl Med. 2015; 56 Suppl 2: 2A-30.

72. Kratochwil C, Giesel FL, Leotta K, Eder M, Hoppe-Tich T, Youssoufian H, et al. PMPA for nephroprotection in PSMA-targeted radionuclide therapy of prostate cancer. J Nucl Med. 2015; 56: 293-8.

73. Weineisen M, Simecek J, Schottelius M, Schwaiger M, Wester HJ. Synthesis and preclinical evaluation of DOTAGA-conjugated PSMA ligands for functional imaging and endoradiotherapy of prostate cancer. EJNMMI Res 2014; 4: 63.

74. Weineisen M, Schottelius M, Simecek J, Baum RP, Yildiz A, Beykan S, et al. 68Ga- and 177Lu-labeled PSMA I\&T: Optimization of a PSMA targeted theranostic concept and first proof of concept human studies. J Nucl Med. 2015; 56: $1169-76$

75. Herrmann K, Bluemel C, Weineisen M, Schottelius M, Wester HJ, Czernin J, et al. Biodistribution and radiation dosimetry for a probe targeting prostate-specific membrane antigen for imaging and therapy. J Nucl Med. 2015; 56: $855-61$.

76. Neuman BP, Eifler JB, Castanares M, Chowdhury WH, Chen Y, Mease RC, et al. Real-time, near-infrared fluorescence imaging with an optimized dye/light source/camera combination for surgical guidance of prostate cancer. Clin Cancer Res. 2015; 21: 771-80.

77. Maurer T, Weirich G, Schottelius M, Weineisen M, Frisch B, Okur A, et al. Prostate-specific Membrane Antigen-radioguided Surgery for Metastatic Lymph Nodes in Prostate Cancer. Eur Urol. 2015; 68: 530-4.

78. Chen Y, Dhara S, Baneriee SR, Byun Y, Pullambhatla M, Mease RC, et al. A low molecular weight PSMA-based fluorescent imaging agent for cancer. Biochem Biophys Res Commun. 2009; 390: 624-9. 